\title{
Consensuses and discrepancies of basin-scale ocean heat content changes in different ocean analyses
}

\author{
Gongjie Wang ${ }^{1}$ Lijing Cheng ${ }^{2} \cdot$ John Abraham ${ }^{3} \cdot$ Chongyin $\mathrm{Li}^{1,4}$
}

Received: 5 January 2017 / Accepted: 3 June 2017 / Published online: 12 June 2017

(C) The Author(s) 2017. This article is an open access publication

\begin{abstract}
Inconsistent global/basin ocean heat content (OHC) changes were found in different ocean subsurface temperature analyses, especially in recent studies related to the slowdown in global surface temperature rise. This finding challenges the reliability of the ocean subsurface temperature analyses and motivates a more comprehensive inter-comparison between the analyses. Here we compare the OHC changes in three ocean analyses (Ishii, EN4 and IAP) to investigate the uncertainty in $\mathrm{OHC}$ in four major ocean basins from decadal to multi-decadal scales. First, all products show an increase of OHC since 1970 in each ocean basin revealing a robust warming, although the warming rates are not identical. The geographical patterns, the key modes and the vertical structure of OHC changes are consistent among the three datasets, implying that the main $\mathrm{OHC}$ variabilities can be robustly represented. However, large discrepancies are found in the percentage of basinal ocean heating related to the global ocean, with the largest differences in the Pacific and Southern Ocean. Meanwhile, we find a large discrepancy of ocean heat storage in different layers, especially within $300-700 \mathrm{~m}$ in the Pacific and Southern Oceans. Furthermore, the near surface analysis of Ishii and IAP are consistent with sea surface
\end{abstract}

Lijing Cheng

chenglij@mail.iap.ac.cn

1 Institute of Meteorology and Oceanography, PLA University of Science and Technology, Nanjing, Jiangsu, China

2 International Center for Climate and Environment Sciences, Institute of Atmospheric Physics, Chinese Academy of Sciences, Beijing, China

3 University of St. Thomas, St. Paul, MN, USA

4 LASG, Institute of Atmospheric Physics, Chinese Academy of Sciences, Beijing, China temperature (SST) products, but EN4 is found to underestimate the long-term trend. Compared with ocean heat storage derived from the atmospheric budget equation, all products show consistent seasonal cycles of $\mathrm{OHC}$ in the upper $1500 \mathrm{~m}$ especially during 2008 to 2012 . Overall, our analyses further the understanding of the observed $\mathrm{OHC}$ variations, and we recommend a careful quantification of errors in the ocean analyses.

Keywords Ocean heat content . Climate change $\cdot$ Hiatus . EN4 $\cdot$ Ishii $\cdot$ IAP $\cdot$ TOA $\cdot$ SST

\section{Introduction}

An understanding of global and regional ocean heat content $(\mathrm{OHC})$ change is essential to understand both past and future climate change. It has been shown that more than $90 \%$ of the earth's energy imbalance (EEI) in the climate system is sequestered in the ocean (increasing the $\mathrm{OHC}$ ), the rest goes into warming the land and atmosphere and melting ice (Trenberth et al. 2016; von Schuckmann et al. 2016). Therefore, OHC is the most robust indicator of climate change. During the past 30 years, many independent groups worked to estimate historical OHC changes, however large uncertainty has been found among the published global OHC time series (Rhein et al. 2013). The uncertainty is sourced from instrument biases (specially for eXpendable BathyThermograph bias), mapping methods, and definitions of a baseline climatology (Abraham et al. 2013; Cheng et al. 2015b; Boyer et al. 2016). Most of these previous studies focused on global OHC changes (Lyman et al. 2006, 2010; Levitus et al. 2009, 2012; Balmaseda et al. 2013; Lyman and Johnson 2014; Cheng et al. 2015b; 
Roemmich et al. 2015), while the uncertainty of basin-scale OHC remains unknown.

Regional $\mathrm{OHC}$ changes are crucial to understand the energy flows between the ocean basins. For example, during the current surge of research on the so-called "hiatus", some of the essential questions were, "Where is the heat redistributed in the ocean?" and "Which ocean basin is the key driver of the recent slowdown of global surface temperature increase?" (Trenberth and Fasullo 2013; Clement and DiNezio 2014; Trenberth 2015; von Schuckmann et al. 2016). Independent studies have given different observational $\mathrm{OHC}$ changes and then proposed different mechanisms to explain the ocean heat redistribution (Meehl et al. 2011; Kosaka and Xie 2013; England et al. 2014; Balmaseda et al. 2013; Chen and Tung 2014; Drijfhout et al. 2014; Nieves et al. 2015; Lee et al. 2015; Liu et al. 2016). For instance, Chen and Tung (2014) found that ocean warming below $300 \mathrm{~m}$ depth in the Atlantic and Southern Ocean dominated the ocean heat uptake during 1998-2012 period based on both ocean reanalysis dataOcean Reanalysis System 4 (ORAS4) and ocean objective analysis-Ishii data (Ishii et al. 2003). They hence argued that the multidecadal variability of Atlantic Meridional Overturning Current (AMOC) contributed to the movement of heat to deeper layers. Lee et al. (2015) presented an abrupt increase of $\mathrm{OHC}$ in the Indian Ocean due to the enhancement of Indonesian Through Flow (ITF), which accounts for $\sim 70 \%$ of global upper $0-700 \mathrm{~m}$ ocean heat increase since 2003. Nieves et al. (2015) indicated that the cooling in the top 100-m layer of the Pacific Ocean was mainly compensated by the warming within the 100-to300-m layer of the Indian and Pacific Oceans since 2003. Cheng et al. (2015a) gave a distinctive pattern of global OHC change in the interior ocean: cooling in the upper $100-\mathrm{m}$ depth and 300-to-700-m layers, warming in the 100-to-300-m and 700-to-1500-m layers and contributed the opposite warming trend in upper $300-\mathrm{m}$ to the changes in frequency of ENSO warm and cool events.

Apparent discrepancies occur among the literature discussed above. Therefore, it is an urgent scientific issue to revisit the global and basin scale $\mathrm{OHC}$ changes revealed by different data products in order to examine what level of consensus can be achieved when using ocean analyses. What's more, detecting the uncertainty between different datasets will provide a basis for the further improvements of ocean subsurface temperature analyses. In this study, we investigate the basin-scale OHC changes on decadal scales by using three different ocean analyses, providing both the consensus and the discrepancies among the three datasets. It is vital to understand why the discrepancies occur for the different ocean analyses. We use two independent datasets-sea surface temperature (SST), and net radiative flux at the top of atmosphere (TOA) from satellite observations to validate the ocean analyses.

This manuscript is constructed as follows: an introduction of the datasets and methods is presented in Sect. 2. An inter-comparison of the $\mathrm{OHC}$ and the related subsurface thermal structure changes from the three products is made in Sect. 3. In this study, we will compare the global and basin-scale OHC changes by using three different objectively analyzed ocean datasets (Ishii et al. 2003; Good et al. 2013; Cheng and Zhu 2016). The first two datasets are widely used in climate and oceanography studies, and the last one is a new ocean analysis that was a result of a careful evaluation of the impact of insufficient sampling on the temperature reconstruction (Cheng and Zhu 2016; Cheng et al. 2017). Two periods (1998-2012 and 1983-1998) are used to examine the decadal $\mathrm{OHC}$ variation. A summary of this study and an outlook for the future improvement of the ocean analysis are provided in Sect. 4.

\section{Datasets and methodology}

\subsection{Gridded temperature datasets}

Three independent gridded temperature analyses are used in this study, which are briefly introduced below.

Ishii and Kimoto (2009) (hereafter Ishii data) uses a 3-dimensional variational method to fill the data gaps. Biases in expendable bathythermograph (XBT) and mechanical bathythermograph (MBT) data were corrected by their proposed method (hereafter IK09). The result is a monthly mean gridded map for the period of 1945-2012 with $1^{\circ}$ by $1^{\circ}$ horizontal revolution and 24 vertical levels from 0 to $1500-\mathrm{m}$.

The EN4 analysis uses an optimal interpolation method for the reconstruction at each ocean layer, with $1^{\circ}$ by $1^{\circ}$ horizontal revolution and 42 vertical levels from $\sim 5.0-\mathrm{m}$ down to about 5500-m layer (Good et al. 2013). The XBT bias is respectively corrected by using the Levitus et al. (2009) method (L09 for the EN4-L09 analysis) and Gouretski and Reseghetti (2010) method (GR10, in the EN-GR10 analysis).

The IAP analysis is based on the Cheng and Zhu (2016) study from the Institute of Atmospheric Physics (so labeled as IAP). It is then further improved in Cheng et al. (2017). The XBT profiles are corrected by using $\mathrm{CH} 14$ scheme proposed in Cheng et al. (2014). The mapping method is an ensemble optimum interpolation (En-OI) with CMIP5 model simulations providing error covariance and a firstguess. IAP analysis releases the data from 1940 to 2015, however more reliable reconstruction is possible since the late 1950s (Cheng et al. 2017). The horizontal resolution is 
$1^{\circ}$ by $1^{\circ}$ and there are 41 vertical levels from 1 - to $2000-\mathrm{m}$ depths.

The major data source of all the three analyses is WOD (World Ocean Datasets) (Boyer et al. 2013), so they essentially use the same raw data. The differences among the three analyses reveal the uncertainty in the quality-control processes, mapping methods and XBT/MBT correction schemes. IK09 scheme assumes that XBT biases arise from depth error, and then they provide corrections for the XBT depths which are variable with time and probe type. L09 scheme corrects XBT temperatures by examining the temperature difference between XBT and CTD data, and their correction is time variable. GR10 scheme corrects both pure thermal bias and depth error, similar to CH14. And CH14 scheme explicitly accounts for many influencing factors of XBT bias, for instance: probe type, time and ocean temperature. Now the XBT community recommends the $\mathrm{CH} 14$ scheme be used because it currently provides the most appropriate bias correction strategy (Cheng et al. 2016). The mapping methods are the major error source according to a new comprehensive analysis (Boyer et al. 2016), and the XBT bias provides a secondary source of uncertainty.

\subsection{Sea surface temperature datasets}

The NOAA Extended Reconstruction Sea Surface Temperature (ERSST) provides global, monthly SST data with $1^{\circ}$ by $1^{\circ}$ horizontal resolution starting from 1854 . Compared to the previous version, Version 4 uses the more extensive ICOADS Release 2.5 data and improved quality control, bias adjustment, and infilling procedures. Therefore, ERSST-v4 is used in this study.

NOAA's Optimum Interpolation Sea Surface Temperature (OISST, also known as Reynolds' SST) is a series of global analysis products, including the weekly OISST on a $1^{\circ}$ grid to the more recent daily on a $1 / 4^{\circ}$ grid. This analysis merges both satellite and in situ platforms (i.e., ships and buoys) by using an optimum interpolation method. Here we use the OISST data with $1^{\circ}$ by $1^{\circ}$ resolution which derived by a linear interpolation of the weekly optimum interpolation (OI) version 2 fields to daily fields then averaging the daily values over a month.

\subsection{Heat flux datasets}

TOA radiation flux $\left(\mathrm{R}_{\mathrm{T}}\right)$ data are provided by CERES satellite (https://ceres.larc.nasa.gov). The monthly radiative flux dataset-EBAF, is used in this study, with a horizontal resolution of $1^{\circ}$ ranging from 2000 March to 2016 August.

The monthly mean vertical integrated divergence of total energy and tendency of the total energy's vertical integral, which are associated with the atmospheric energy budget, are provided by the ERA-interim datasets with a horizontal resolution of $0.75^{\circ}$ and can be downloaded from http:// www.cgd.ucar.edu/cas/catalog/reanalysis/ecmwf/erai/ index.html. So the surface net heat flux (Fs) is diagnosed from the atmospheric budget equation (Fasullo and Trenberth 2008).

Only the seasonal cycle of Fs the over global ocean is examined and compared with $\mathrm{OHC}$ since it is much more stable compared with inter-annual changes. Surface net heat flux is converted to ocean heat storage $\left(\mathrm{O}_{\mathrm{E}}\right)$ following the description in McKinnon and Huybers (2016).

\subsection{Method}

OHC is calculated by integrating the temperature anomalies within a certain layer as shown in Eq. 1:

$O H C=\int_{h_{1}}^{h_{2}} \rho C_{p} T^{\prime} d z$

where $\rho, C_{p}, T^{\prime}$ are the density of sea water, thermal capacity and temperature anomaly respectively. Parameter $h_{1}$ and $h_{2}$ definite the lower and upper limits of the layer depth. In this study, the maximum value for $h_{1}$ is set as $1500-\mathrm{m}$, which is the maximum depth of Ishii analysis. The values of $\boldsymbol{\rho}$ and $C_{p}$ are calculated from monthly temperature and salinity fields in Ishii and EN4 data, and we use the climatological salinity from WOA13 in the IAP analysis. The linear trend in $\mathrm{OHC}$ is calculated by a least square regression and the error is two times standard error.

A 12-month climatology is constructed by averaging data from 2008 to 2012. Then it is subtracted from the temperature field to remove the seasonal cycle (Cheng and Zhu 2015). A 12-month running mean is further applied to filter high-frequency signals from the monthly $\mathrm{OHC}$ time series since a recent study indicates that the monthly variation of $\mathrm{OHC}$ changes in ocean analyses are mostly nonphysical (Trenberth et al. 2016). In this study, the global ocean is divided into the Southern, Pacific, Atlantic, and the Indian Oceans as in Lee et al. (2015), except that the Southern Ocean is connected with other basins at $35^{\circ} \mathrm{S}$.

\section{Results}

In this section, global and regional $\mathrm{OHC}$ changes based on the three products are shown (Sect. 3.1). To examine the decadal variations, we focus on two periods: 1983-1998 and 1998-2012, the latter is typically referred as the slowdown period in the literature. Geographical patterns of OHC changes are discussed in Sect. 3.2. In Sect. 3.3, 
temperature changes for different ocean layers are shown and will be used to provide an indication for the vertical heat distribution. Further comparisons with two kinds of independent datasets are provided in Sect. 3.4.

\subsection{Time evolution of $\mathrm{OHC}$}

Global OHC time series for the upper 1500-m since 1970 are presented in Fig. 1, accompanied with OHC changes in the four major ocean basins: the Atlantic, Southern, Pacific, and Indian Oceans. It appears that $\mathrm{OHC}$ varies on different time scales ranging from interannual, decadal to multi-decadal scales. On a multi-decadal scale, there is a pronounced increase in OHC since 1970, which is robust globally and in all four major basins. This indicates a robust fingerprint of global warming due to the persistent positive radiative imbalance (Loeb et al. 2012; Allan et al. 2014) since the global ocean stores the majority of the heat of Earth's energy imbalance (Trenberth et al. 2014a, b). However, the long-term trend of global OHC from 1970 to 2012 reveals

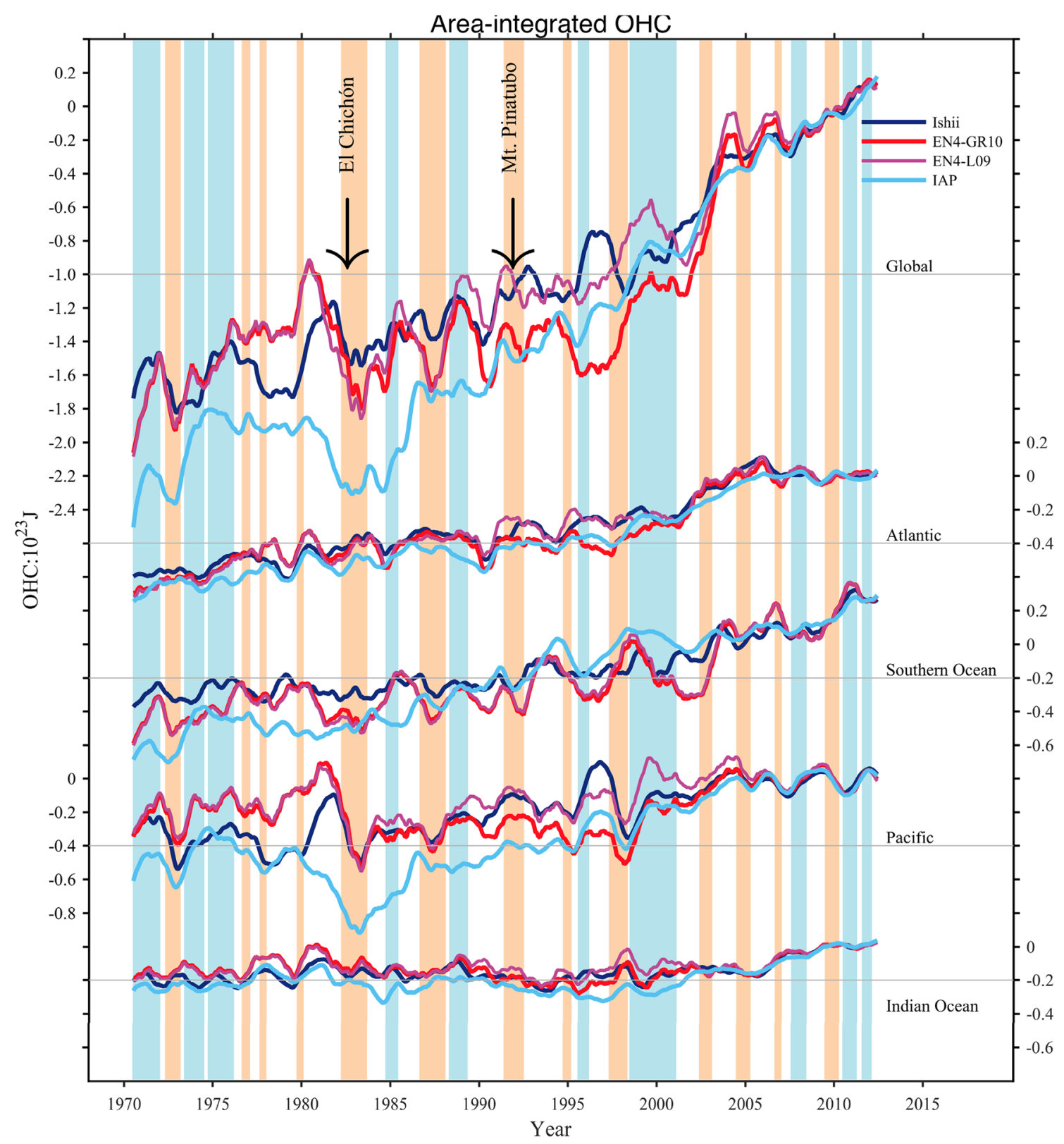

Fig. 1 Monthly ocean heat content (OHC) time series integrated from the surface to the 1500-m layer in the global, Atlantic, Southern, Pacific and Indian Oceans from four datasets. 12-month running means have been used to filter high frequency signals. Marked on the graph are the El Niño (tan) and La Niña (blue) periods as defined by NOAA's ONI, based on the SST anomalies in Nino 3.4 region (https://www.esrl.noaa.gov/psd/data/climateindices/list/). Two major volcanic eruptions in March 1982 and July 1991 are also marked 
substantial differences, varying from 0.43 (Ishii), 0.39 (EN4-GR10) to 0.59 (IAP) with common unit of $10^{23} \mathrm{~J}$ per decade. Three products show very similar $\mathrm{OHC}$ changes for both global and basinal OHC changes since 2005 (Fig. 1) because the Argo network greatly increases the ocean subsurface observations and increases the reliability of $\mathrm{OHC}$ estimates (Johnson et al. 2015; Wijffels et al. 2016; Riser et al. 2016).

Regarding decadal $\mathrm{OHC}$ changes, quantification of $\mathrm{OHC}$ in each ocean basin in the two successive periods gives implications about ocean heat redistribution on decadal scales. For the 1983-1998 period, the global OHC linear trend (Fig. 2) ranges from $0.066 \times 10^{23} \mathrm{~J} /$ decade (EN4-GR10) to $0.73 \times 10^{23} \mathrm{~J} /$ decade (IAP), showing large discrepancies among the three datasets. OHC estimates in the Atlantic and Indian Ocean are more consistent among the three products than in the Pacific $\left(0.033-0.36 \times 10^{23} \mathrm{~J} /\right.$ decade) and the Southern Ocean $\left(0.096-0.33 \times 10^{23} \mathrm{~J} /\right.$ decade), indicating that the major uncertainty in global OHC changes comes from the Pacific Ocean and Southern Ocean. It is possible that larger uncertainty in these two ocean basins arise from their area or the sparse observations especially for the Southern Ocean and we will give a detailed analysis in the following Sect. 3.4.3.

During the 1998-2012 period, trends of global OHC are much more consistent, varying from 0.81 to $1.0 \times 10^{23} \mathrm{~J} /$ decade (Fig. 2). It is still a question which ocean basin has sequestered more heat during the recent hiatus period than prior to that time? In the Atlantic and Indian Ocean, all datasets show a robust acceleration of $\mathrm{OHC}$ increase during the recent decade compared with 1983-1998. The Pacific Ocean shows a slowdown of OHC increase during the 1998-2012 period for the IAP and Ishii data (not for EN4-GR10). And the Southern Ocean experiences a slight slowdown of OHC increase in the IAP data but significant increase for EN4-GR10 and Ishii analysis. This finding indicates that, although heat accumulation is evident in the global ocean, the basinal OHC change is still uncertain among different datasets.

The relative contribution of each ocean basin to global ocean heat uptake is shown in Fig. 3. During 1983-1998, the Pacific Ocean dominates the global ocean heat uptake in the Ishii and IAP analyses, but EN4-GR10 data shows a dominance of the Southern and the Indian Oceans. By contrast, during 1998-2012, Ishii and EN4-GR10 data show that the Atlantic and Southern Oceans account for the majority of global ocean heat uptake while IAP data indicates a more uniform contribution from each ocean basin. Shifting the start and end points by 2 years does not alter the conclusions.

These results suggest there is no consensus quantification of the difference of $\mathrm{OHC}$ changes in the recent decade compared with the previous decade on a basinal scale, because of the large uncertainty in OHC estimates in the early period such as 1983-1998 and also in the Pacific and Southern Ocean in the recent decade.

On inter-annual scales, both ENSO and the eruption of volcanoes are dominant mechanisms responsible for the OHC changes (Balmaseda et al. 2013; Trenberth et al. 2014a). El Niño events contribute to heat loss from
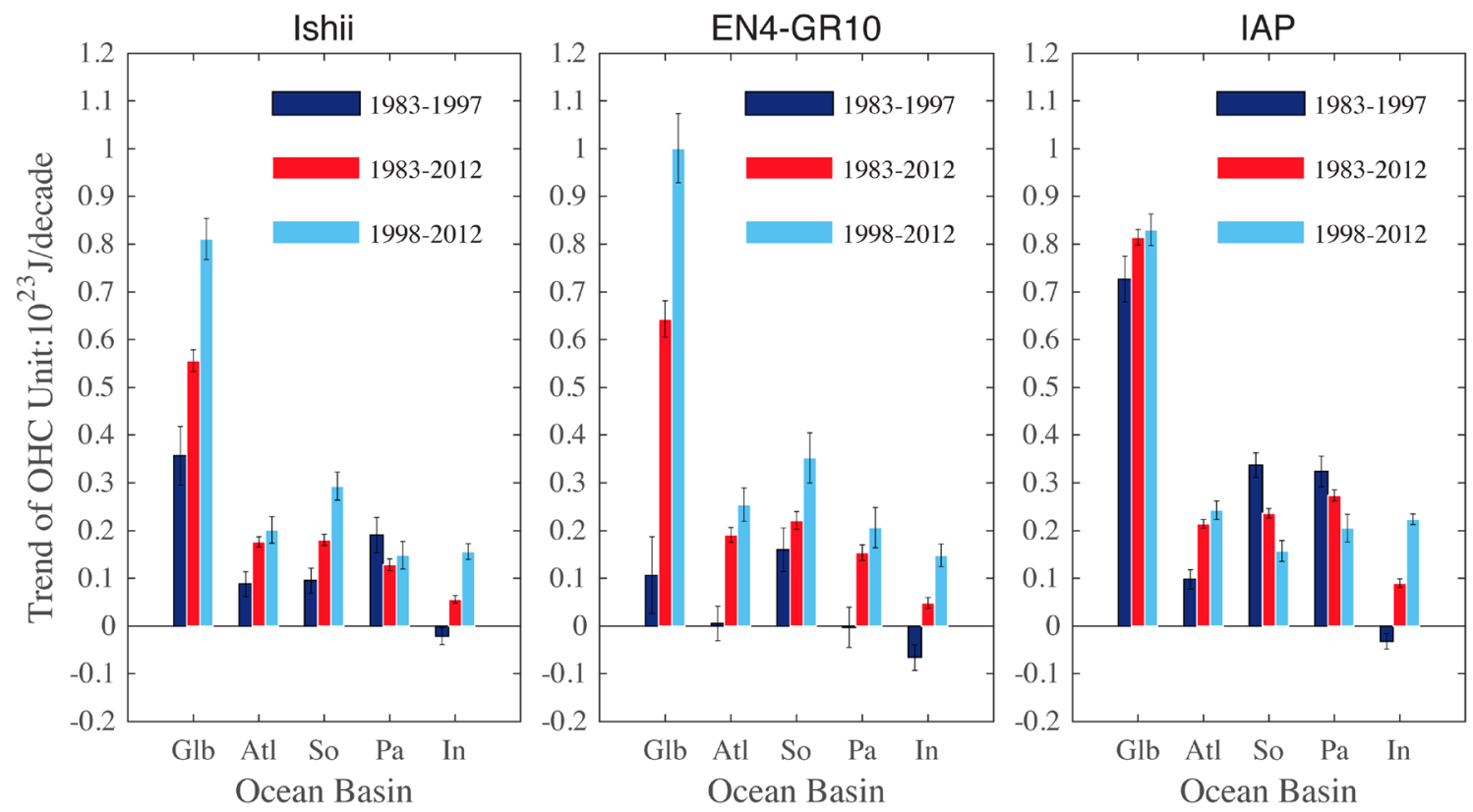

Fig. $2 \mathrm{OHC}$ trend in the Global ocean and in different ocean basins during different time periods, with error bars showing two times standard error, Glb, Atl, So, Pa and In are abbreviations for globe, Atlantic, Southern, Pacific, and Indian Ocean respectively 
Fig. 3 Relative contribution of each ocean basin to global OHC changes (OHC 0-1500 m) for two successive periods: 1983-1998 (left) and 19982012 (right)

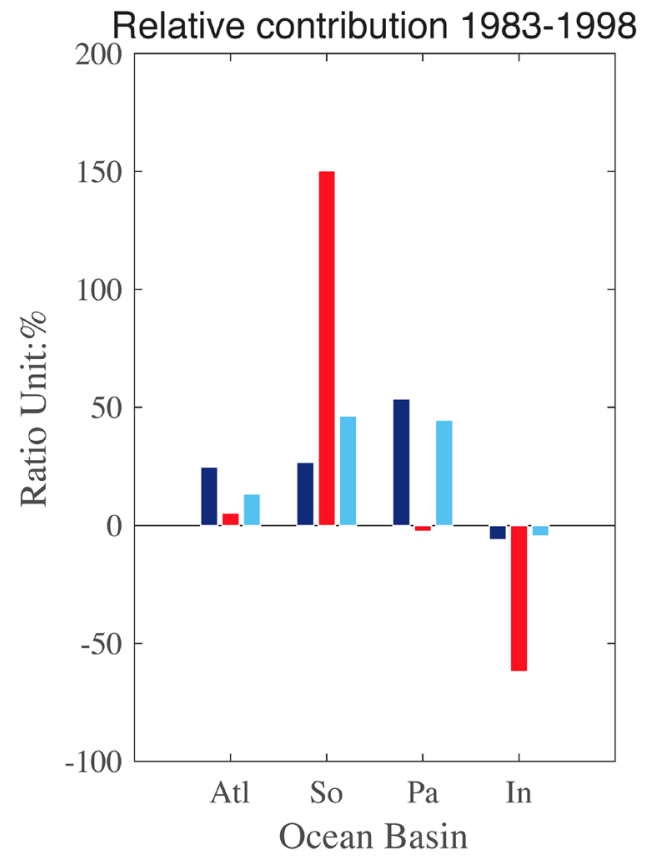

the ocean to the atmosphere, while La Niña events give the reverse (Fasullo and Nerem 2016). Volcanic eruptions increase aerosols in the atmosphere which reduce the absorption of short wave solar energy, leading to a net heat loss in the Earth system (Church et al. 2005). Figure 1 marks the El Niño and La Niña events since 1970, typically the OHC decreases (increases) during El Niño (La Niña) events. All products show an OHC decrease after the El Chichón volcano eruption in March 1982. However, when Mt. Pinatubo erupted in July 1991, EN4-GR10 and IAP data show a weak decrease in global $\mathrm{OHC}$, which is absent in Ishii data.

Although the radiative forcing changes arising from Mt. Pinatubo is significantly greater than that of El Chichón, the OHC decrease after El Chichón is much larger, which is evident for all datasets. It has been shown in Cheng et al. (2017) that the OHC variability on inter-annual scale is comparable with error due to insufficient ocean sampling (signal/noise ratio less than 2). Therefore, it is possible that the weaker $\mathrm{OHC}$ signal after Mt. Pinatubo is linked to sampling error. Moreover, it is possible that XBT also contributes because the XBT bias for each year is calculated by combining several years' data together (i.e. 5-years in CH14), where the year-to-year variation of XBT bias is underestimated. In addition, these two volcanic eruptions were coincident with 1982/83 and 1991/92 El Niño events respectively. The stronger magnitude of the 1982/82 El Niño event may account for the larger OHC changes in the Pacific and global ocean. The associated $\mathrm{OHC}$ changes arise from both ocean internal variability and external forcing and separating the impact of the two phenomena is complicated and beyond the scope of this study.
What's more, we compare the global and basin-integrated OHC changes estimated from EN4-L09 and EN4GR10 (Fig. 1). The difference between the two datasets is only due to XBT bias, since the data source, quality control process, mapping method, and the climatology are the same. In global and each ocean basin, there is a significant difference between the two XBT correction methods from 1980 to 2000: the maximum OHC difference is $\sim 0.5 \times 10^{23} \mathrm{~J}$ around 1995 . However, the total OHC change since 1970 is $\sim 2 \times 10^{23} \mathrm{~J}$. This highlights the importance of XBT bias corrections in OHC calculation, and indicates the XBT bias is still the major error source in ocean subsurface temperature analysis. Boyer et al. (2016) comprehensively examined the uncertainty in $\mathrm{OHC}$ estimates due to XBT biases correction schemes, mapping methods and the definitions of climatology. They found that mapping method was the largest source of uncertainty. We also used L09 correction in IAP dataset, showing a very similar OHC time series as current IAP OHC (figure not shown), which shows much stronger long-term trend than EN4-L09, confirming that the mapping method is another major source of error. Differences in OHC time series provided in this study most likely arise from a combined effect of many factors and deserves further in-depth study.

\subsection{Geographical pattern of long-term $\mathrm{OHC}$ changes}

As there are some discrepancies for the inter-annual and decadal scale OHC changes in different ocean basins, it remains to be seen whether a robust geographical pattern of $\mathrm{OHC}$ changes can be obtained. Figure 4 shows the linear trends of $\mathrm{OHC}$ changes in each $1^{\circ}$ by $1^{\circ}$ grid box for 


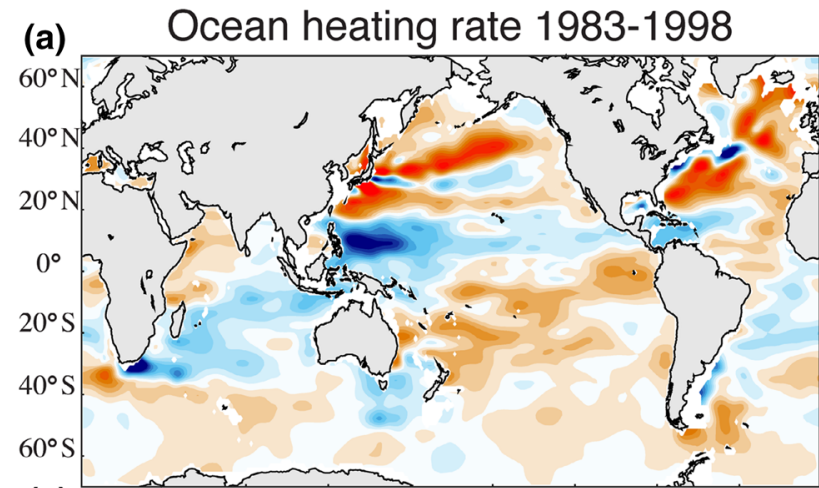

(c)

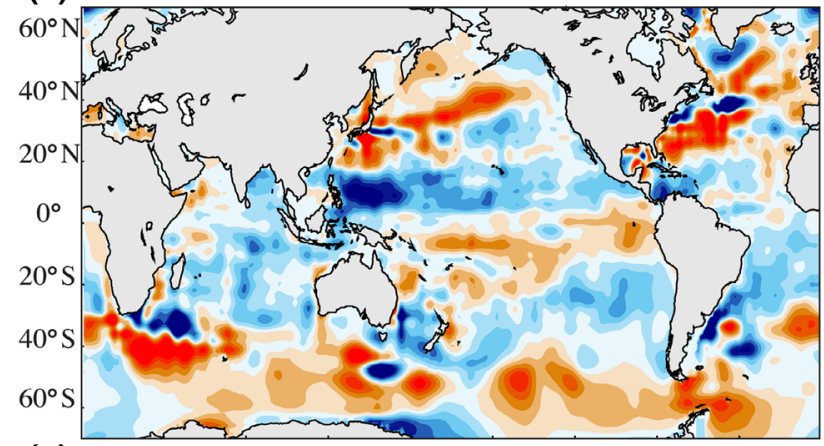

(e)

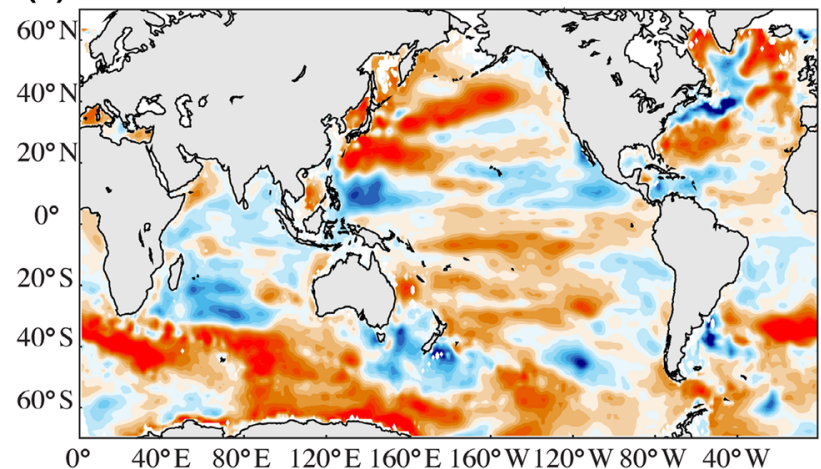

(b)

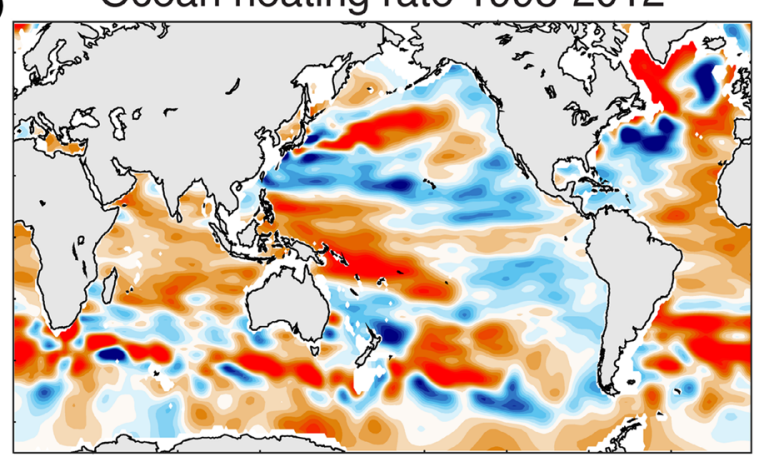

(d)

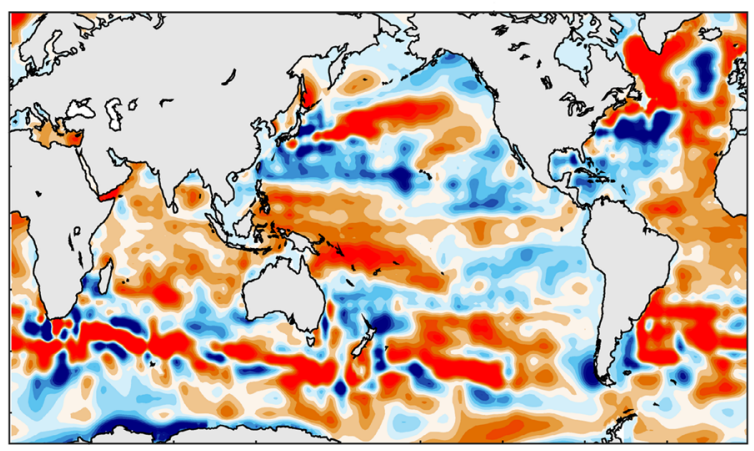

(f)

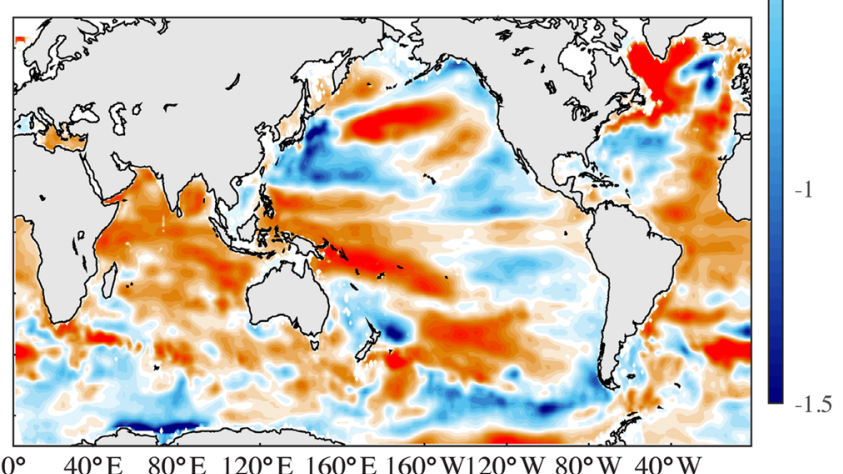

Fig. 4 Linear trend of $\mathrm{OHC}$ change in each $1^{\circ}$ by $1^{\circ}$ grid for two successive periods (the left panel for the 1983-1998 period, the right panel for the 1998-2012 period), with $\mathbf{a}$ and $\mathbf{b}$ for Ishii, $\mathbf{c}$ and $\mathbf{d}$ for EN4-GR10, $\mathbf{e}$ and $\mathbf{f}$ for IAP. Unit: $10^{8} \mathrm{~J} /$ year

1983-1998 and 1998-2012 periods separately. Generally, all three products show a consistent pattern of $\mathrm{OHC}$ changes in each decade. Although globally integrated ocean has gained heat continually during the past several decades, the heating magnitude varies regionally and parts of the ocean even lose heat. During the 1983-1998 period, ocean warming is evident in the Southern Pacific, Southern Ocean and middle latitudes in the Atlantic and North Pacific Ocean. The Indian Ocean is cooling except in Arabian Sea.

Ishii data show much weaker trends in the Southern Ocean than the other two products, and the variability is also much weaker than the other regions, which are likely nonphysical; The Southern Ocean is characterized by the shape fronts near the Antarctic Circumpolar Current (ACC) regions where many eddies occur. In addition, data is sparse in the Southern Ocean, and the gap-filling method of Ishii data is weak at reconstructing the variability in such regions. In the recent decade, due to more data in this region, Ishii data show comparable spatial variability in the Southern Ocean with the other datasets.

During the 1998-2012 period, more consistency in OHC change can be found among the three datasets. Now we are able to give a more detailed picture about the heat redistribution during the past several decades. There are positive $\mathrm{OHC}$ increases in the Indian, western tropical Pacific, subtropical Pacific, and tropical Atlantic Oceans (Fig. 4). Therefore, it appears that there is no single ocean basin that is solely responsible for the ocean heat uptake. Instead, the heat is redistributed in the different ocean basins. The 
different studies discussed in the Sect. 1 of this study are not actually contradictory with each other, and they all show a piece of the big picture. For example, Lee et al. (2015) addressed the enhanced Indonesian through flow (ITF), which might be mainly responsible for the Indian Ocean warming. Neives et al. (2015) indicated the Indian and tropical Pacific are warming. And Chen and Tung (2014) highlighted the Atlantic warming. However, it remains a question about what mechanisms drive the ocean heat redistribution and form the OHC pattern as shown in Fig. 4 (Yan et al. 2016).

As empirical orthogonal function (EOF) analysis is widely used to detect the key modes of variability (Deser et al. 2010), this tool will be employed to determine whether the three products show consistent dominant modes of $\mathrm{OHC}$ variation. Here we calculate the first three modes of the OHC changes through EOF analysis. In order to filter out high-frequency noise in $\mathrm{OHC}$ analyses, we calculated a 12-months running mean before the EOF analysis. Generally, the three datasets show a consistent geographical pattern of the first three EOF modes (Fig. 5), although there are some differences in the smoothness of the patterns especially in the Southern Ocean. The first two modes all show an ENSO-like pattern in the Pacific
Ocean, mimicking the Pacific Decadal Oscillation (PDO) or Inter-decadal Pacific Oscillation (IPO) patterns in the pan-Pacific. And the third modes show a strong band-like pattern in the Pacific: negative anomalies in the tropics and mid-latitudes, positive anomalies in the subtropical North Pacific and Southeast Pacific. Smaller scale phenomena appear in Ishii and EN4-GR10 compared to the IAP analysis, probably due to different correlation length scales used in the mapping methods.

The time series of the associated principle components (PCs) are shown in Fig. 6. We compare the PC time series with the indexes of the two main climate internal decadal variabilities: IPO indicated by IPO index (Henley et al. 2015) and Atlantic Multi-decadal Oscillation (AMO) indicated by AMO index (Enfield et al. 2010). Both PC1s and PC2s correlate with both IPO and AMO indices with the correlation coefficients varying from 0.41 to 0.68 . The correlation between PCs and IPO/AMO indices (Table 1) indicates that IPO and AMO may play an important role in the global OHC changes (Trenberth and Fasullo 2013; Chen and Tung 2014; Drijfhout et al. 2014), although the mechanisms of OHC changes related to AMO/IPO are still unclear and require further examination. (a)

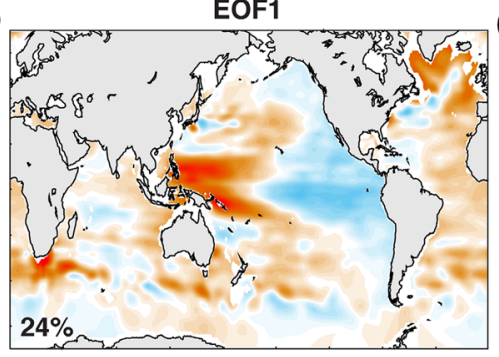

(d)

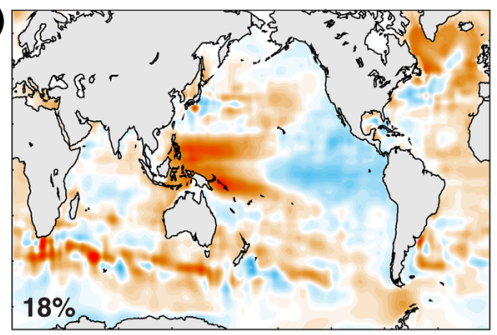

(g)

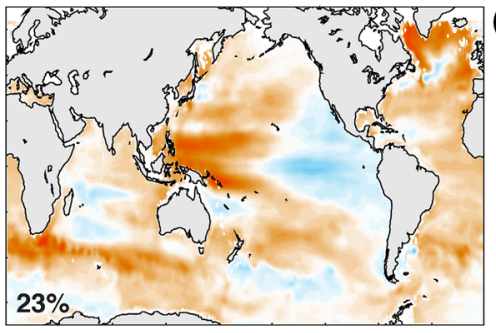

(b)

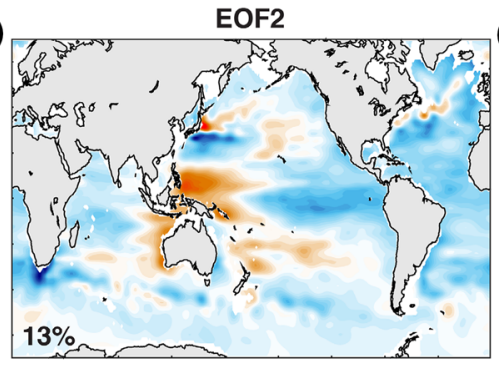

(e)

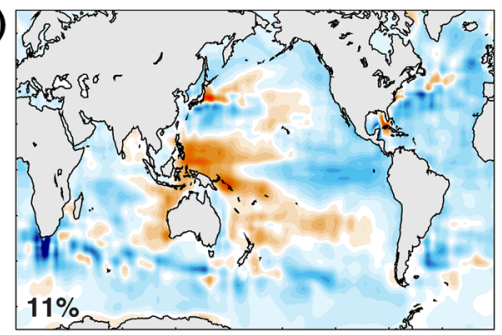

(h)

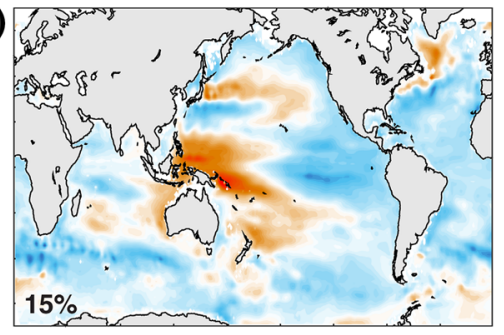

(c)

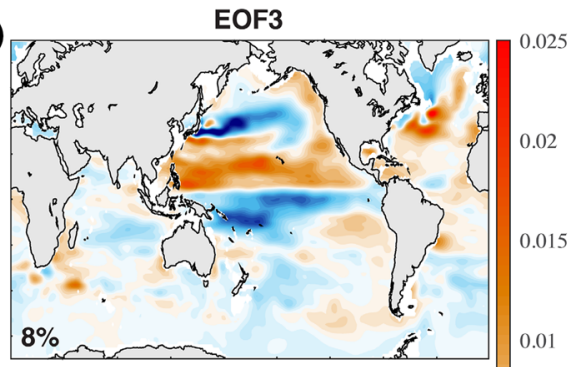

(f)

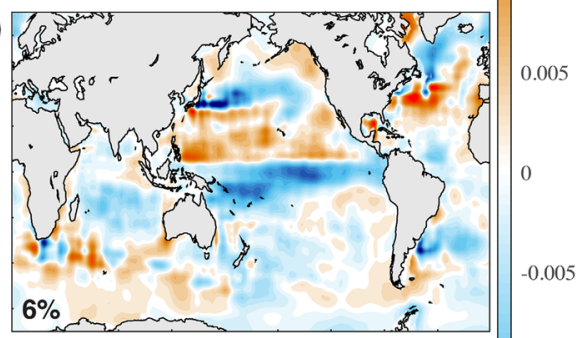

(i)

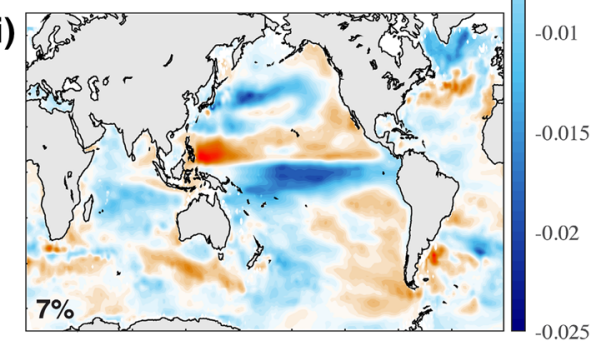

Fig. 5 Leading, secondary and third modes calculated by the empirical orthogonal functions (EOFs) of monthly OHC (0-1500-m) over the global oceans based on the three datasets during 1970-2012: a-c for Ishii; d-f for EN4-GR10; $\mathbf{g}-\mathbf{i}$ for IAP 
Fig. 6 Principal component (PC) time series corresponding two the first three modes of the EOF analysis compared with two key climate indexes (dashed lines). a Shows the leading mode, $\mathbf{b}$ for the secondary mode and $\mathbf{c}$ for the third mode. Solid lines with different colors are the PC time series from different datasets. All of these climate indices are provided by Earth System Research Laboratory from NOAA (National Oceanic and Atmospheric Administration) and can be downloaded freely from the website: http:// www.esrl.noaa.gov/psd/data/ climateindices/list/
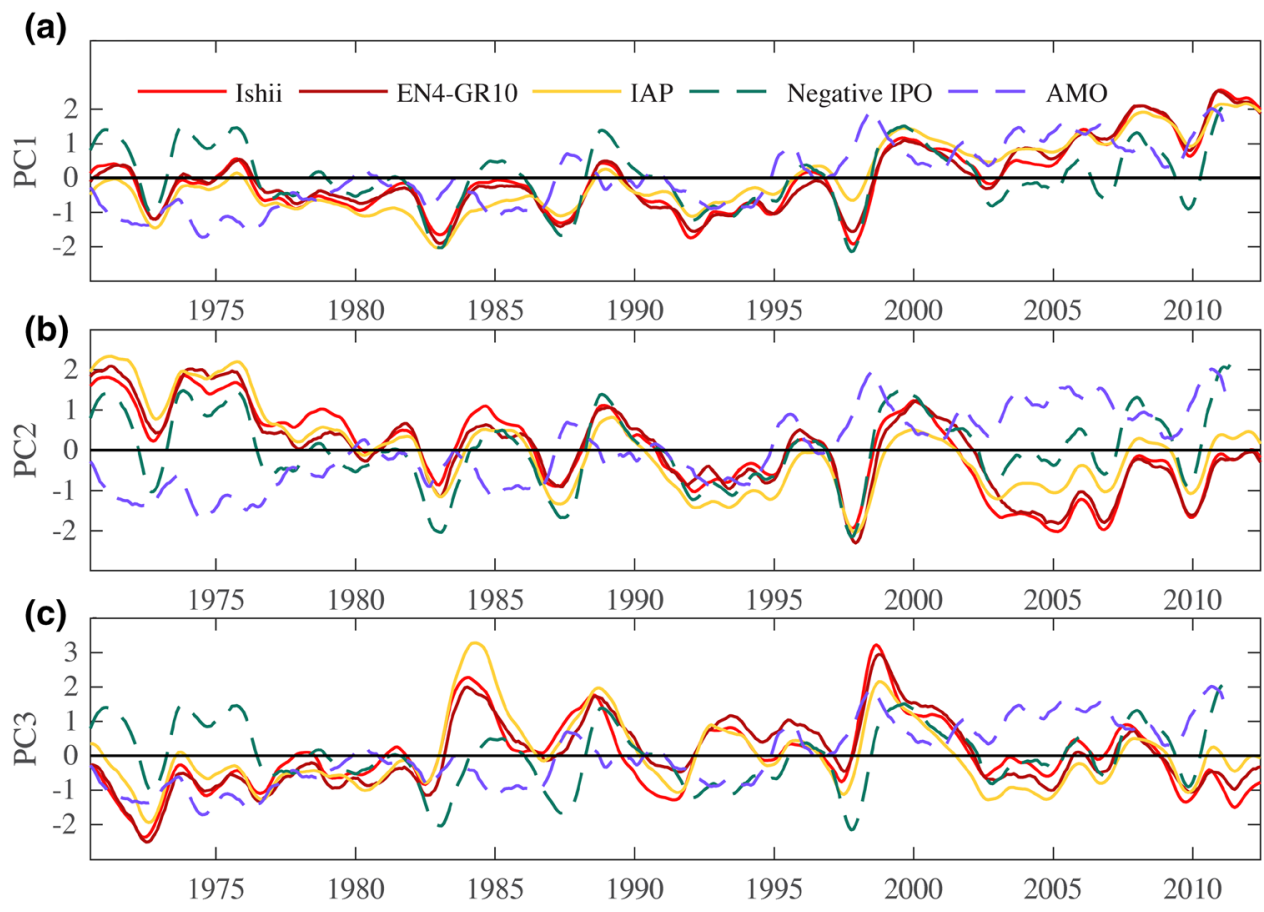

Table 1 The correlation coefficient between PC-1s and two climate indexes

\begin{tabular}{lll}
\hline & IPO & AMO \\
\hline Ishii & $0.68(0.58)$ & $0.41(0.57)$ \\
EN4-GR10 & $0.65(0.62)$ & $0.43(0.57)$ \\
IAP & $0.52(0.67)$ & $0.58(0.50)$ \\
\hline
\end{tabular}

The correlation coefficients between PC-2s and two climate indexes are shown inside the brackets

In summary, three datasets show consistent key modes of historical OHC variability since 1970 (PC-1, PC-2 and PC-3), suggesting a possibility to examine the driver of $\mathrm{OHC}$ changes in the future by either dataset.

\subsection{OHC changes in different ocean layers}

$\mathrm{OHC}$ is an integration of ocean temperature changes, so it is valuable to examine its change at different depths to identify the source of uncertainty. Here we calculate the $\mathrm{OHC}$ trends for each depth during both the 1983-1998 (Fig. 7) and 1998-2012 periods (Fig. 8). Four vertical layers are examined here: the upper 100-, 100-300-, 300-700-m and below 700-m, similar to Cheng et al. (2015a). During the 1983-1998 period, three datasets show very large differences, for instance: for the upper 100-m, IAP and Ishii show a strong warming for the global ocean (up to $1.6 \times 10^{19} \mathrm{~J} /$ year), but EN4-GR10 shows a near-zero trend. This difference is sourced from Pacific and Indian Ocean
(Fig. 7d, e). Weaker trends near the surface in EN4-GR10 data than the other datasets will be discussed in Sect. 3.4 compared with SST datasets. Within the 300-700-m layer, Ishii and EN4-GR10 show near-zero trend while IAP presents a strong warming which is largely due to the Southern Ocean and the Pacific Ocean (Fig. 7c, d). Below 700-m, Ishii and IAP show ocean warming while EN4-GR10 lacks warming. This behavior is also attributed to the differences in the Southern Ocean and Pacific Ocean (Fig. 7c, d).

The Indian Ocean and Atlantic Ocean are the regions with less uncertainty than the Southern Ocean and Pacific Ocean, consistent with our findings in the previous sections (i.e. Fig. 1 in Sect. 3.1). It is interesting that the largest differences among the three datasets occur in 300-700-m in the Southern and Pacific Oceans, which contains the sparsest data coverage. This suggests that mapping is still a major error source in ocean subsurface temperature reconstructions, and a comprehensive examination for the current existing mapping methods is required.

In the most recent decade, within 1998-2012, there is much better consistency among the three products than the 1983-1998 period. The upper 100-m experienced a weak warming (IAP and Ishii) or cooling (EN4-GR10), coincident with the global surface temperature slowdown discussed in recent literature (Xie 2016). This 0-100-m warming slowdown is accompanied with a large subsurface warming within $100-300-\mathrm{m}$, which is consistent among these three datasets. The global structure in the upper $300 \mathrm{~m}$ is dominated by the temperature changes in the Pacific Ocean (Fig. 7d), suggesting that the Pacific 
(a) Trend Unit: $10^{19} \mathrm{~J} / \mathrm{yr}$

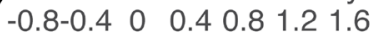

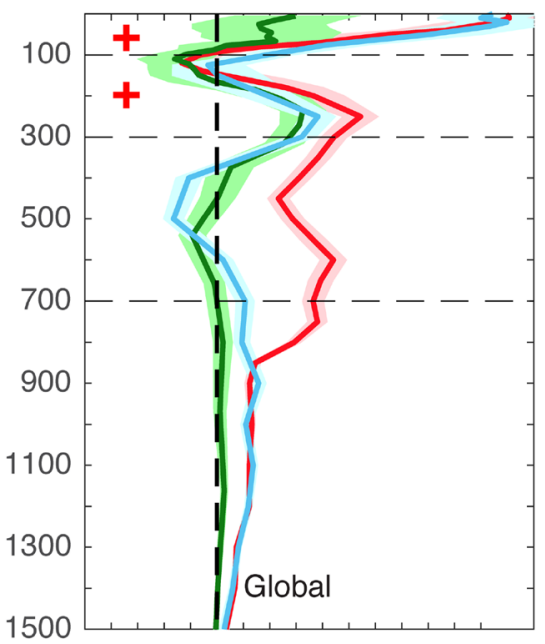

(d) Trend Unit: $10^{19} \mathrm{~J} / \mathrm{yr}$ $\begin{array}{llllllll}-0.8 & -0.4 & 0 & 0.4 & 0.8 & 1.2 & 1.6\end{array}$

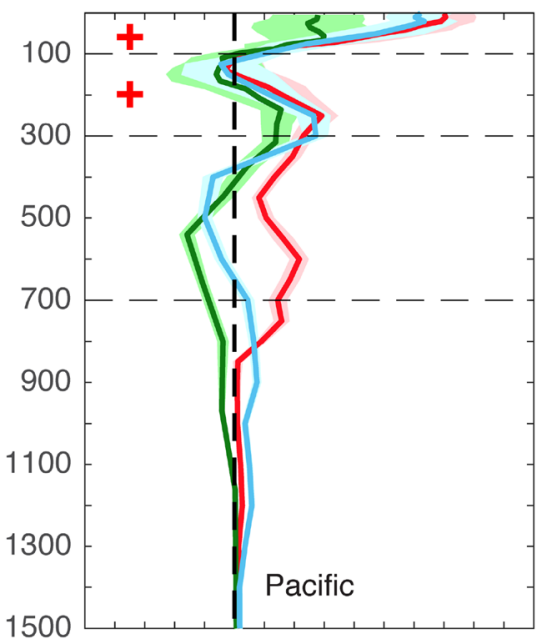

(b) Trend Unit:10 $19 \mathrm{~J} / \mathrm{yr}$ $\begin{array}{lllllll}-0.8 & -0.4 & 0 & 0.4 & 0.8 & 1.2 & 1.6\end{array}$

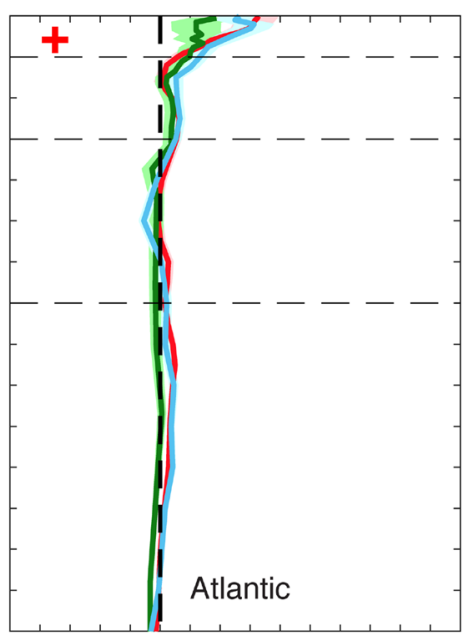

(c) Trend Unit:10 $19 \mathrm{~J} / \mathrm{yr}$ $\begin{array}{lllllll}-0.8 & -0.4 & 0 & 0.4 & 0.8 & 1.2 & 1.6\end{array}$

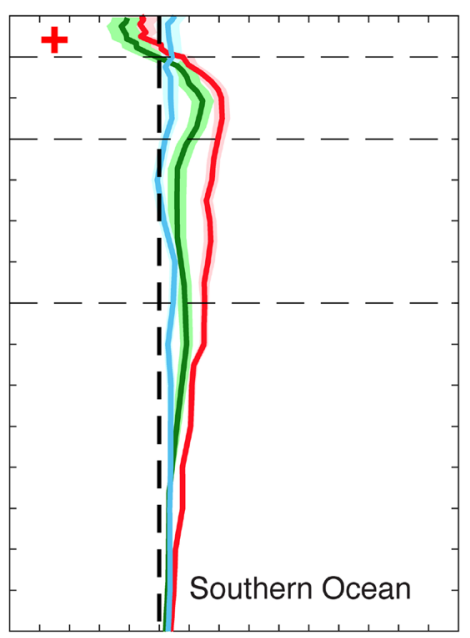

(e) Trend Unit:10 $19 \mathrm{~J} / \mathrm{yr}$ $\begin{array}{lllllll}-0.8 & -0.4 & 0 & 0.4 & 0.8 & 1.2 & 1.6\end{array}$

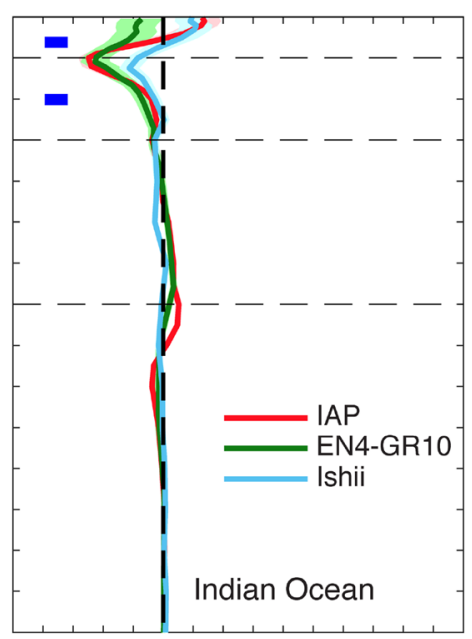

Fig. 7 Ocean heating rate at different depths during 1983-1998 period, a for global ocean, b for Atlantic Ocean, c for Southern Ocean, d for Pacific Ocean, and e for Indian Ocean. 2- $\sigma$ (uncertainty) is indicated by shading

Ocean may play a dominant role in controlling the global ocean changes in the upper 300-m as found in Cheng et al. (2014). Below 300-m, both Atlantic and Southern Oceans experience a robust warming down to 2000-m, while the Pacific Ocean (Indian Ocean) shows near-zero warming below 300-m (700-m). The three datasets show the largest difference in the Southern Ocean than the other basins, partly because the Argo network is still sparse in ice-covered regions and also might be due to the uncertainty during 1998-2005 period due to the transfer in ocean observation systems (Cheng and Zhu 2014).

In summary, prior to 1998 , the temperature changes in Global, Pacific, Southern Oceans show large discrepancies among products, hindering a robust detection of both regional and global OHC changes. Since 1998, all datasets show consistent variation of temperature change in the upper $1500-\mathrm{m}$, although the magnitude of the changes is different, especially in the Southern Ocean. Now the Argo community is working to improve the Argo coverage in the ice-covered regions which will potentially increase the data coverage in the Southern Ocean and then improve the OHC assessment.

\subsection{Comparison with independent datasets}

We compared the OHC changes among the three products in the previous section. Inter-comparison with independent datasets might give a helpful insight into the data quality. 
(a) Trend Unit: $10^{19} \mathrm{~J} / \mathrm{yr}$

(b) Trend Unit: $10^{19} \mathrm{~J} / \mathrm{yr}$

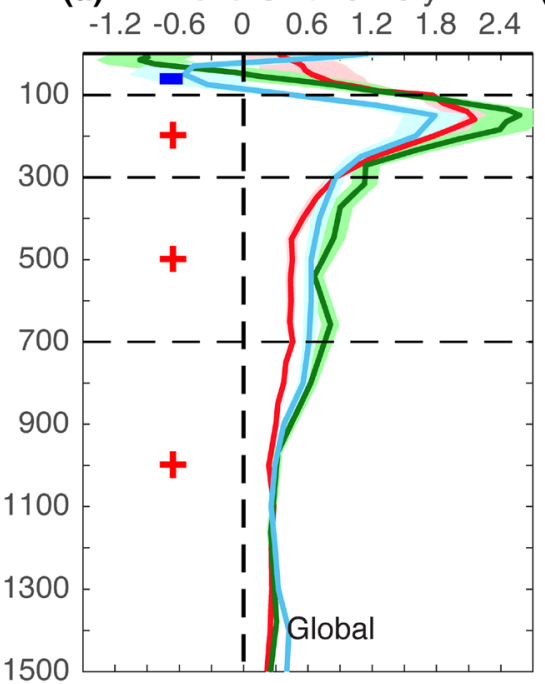

(d) Trend Unit: $10^{19} \mathrm{~J} / \mathrm{yr}$

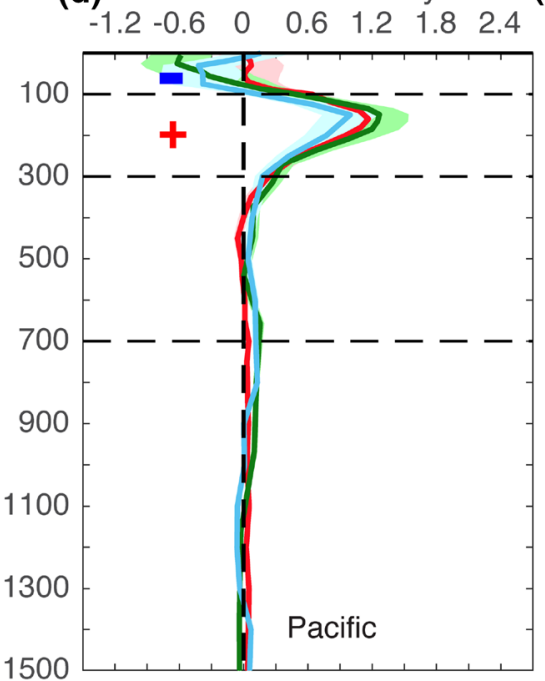

(e) Trend Unit: $10^{19} \mathrm{~J} / \mathrm{yr}$
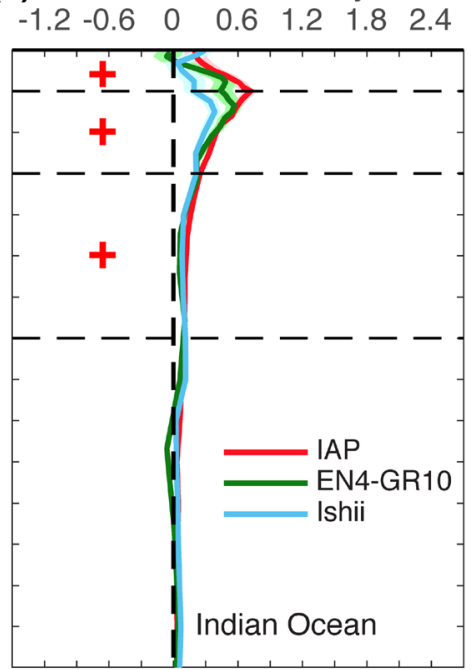

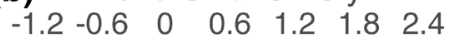

(c) Trend Unit: $10^{19} \mathrm{~J} / \mathrm{yr}$
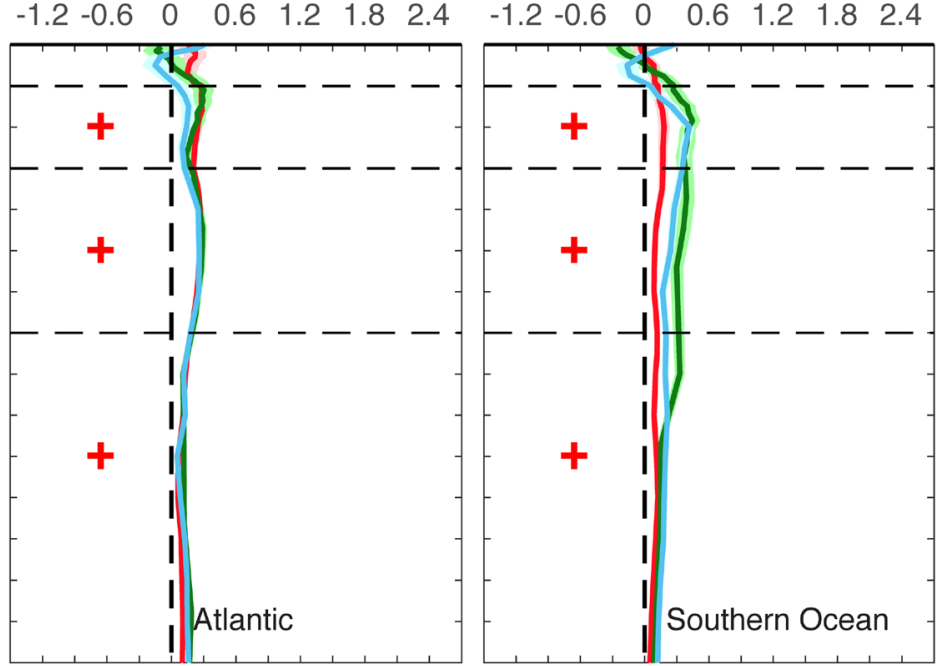

Fig. 8 Ocean heating rate as a function of depth during 1998-2012 period, a global ocean, b Atlantic, $\mathbf{c}$ the Southern Ocean, $\mathbf{d}$ Pacific and $\mathbf{e}$ the Indian Ocean. 2- $\sigma$ uncertainty is indicated by shading

State-of-art SST datasets are used to assess the surface reconstruction of the three datasets. And also we compared the seasonal cycle of the radiative imbalance at the top of the atmosphere with that of $\mathrm{OHC}$ analyses, since $\mathrm{OHC}$ is the major contribution of the radiative imbalance in the Earth system.

\subsubsection{Near surface sea temperatures}

Figure 9 shows the time series of the temperature change at the first level in EN4-GR10, Ishii and IAP data, compared with three SST time series from different international groups. Large interannual variability linked to ENSO is embedded with the long-term warming, as revealed by all products. When calculating a linear trend since 1998, all datasets show a slowdown of SST increase compared with the 1983-1998 period. However, EN4-GR10 shows much smaller trends than the other datasets for both 1983-1998 and 1998-2012 periods. The EN4-GR10, as an outliner, is likely biased in their mapping method, however the reason is still unknown. Again, differences in mapping methods might be mainly responsible for this difference.

\subsubsection{Seasonal cycle of $\mathrm{OHC}$}

The net air-sea heat exchange directly links the ocean and atmosphere and helps determine the changes of global OHC. The surface net heat flux, derived from the 

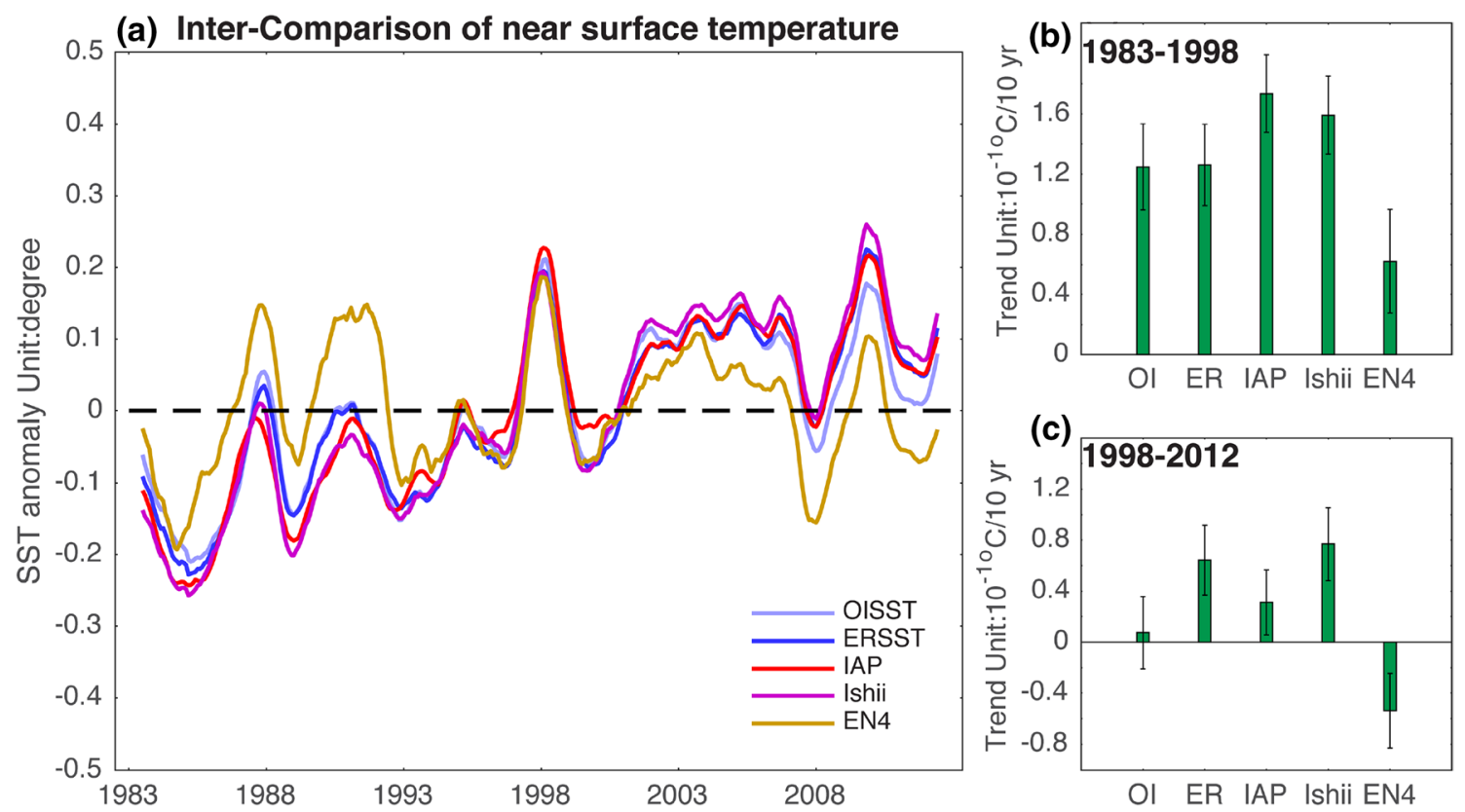

Fig. 9 a The global mean sea surface temperature anomaly time series revealed by five kinds of datasets: Ishii, EN4-GR10, IAP, OISST and ERSST data with different color. b Linear trend for 1983-1998. c Linear trend for 1998-2012

atmospheric energy budget equation, can be used to evaluate seasonal cycles of the global OHC. The seasonal cycle is calculated by retaining the annual and semi-annual harmonics of the monthly time series through least-square fitting. Here it is assumed that there is a stable seasonal cycle for net air-sea heat flux.

A consistent seasonal cycle is displayed in Fig. 10: ocean releases heat from boreal spring to autumn, and traps heat from boreal autumn to spring. The peak of the seasonal cycle of $\mathrm{OHC}$ occurs in April due to the asymmetric distribution of ocean and land in Northern and Southern Hemisphere. A short-period climatology (constructed by data during 2008-2012, Clim2008-2012) and a long-period climatology (using data within 1970-2012, Clim1970-2012) are both shown in Fig. 10. For Ishii and EN4-GR10 analyses, the amplitudes of observational OHC become smaller and more consistent with that derived from surface net heat flux during 2008-2012 period, while IAP
Fig. 10 Seasonal cycles of global $\mathrm{OHC}$ calculated from objective analyzed temperature datasets and time integral of surface net heat flux (EBAF + ERA). a Uses a long-period climatology during 1970-2012, comparing with b for a short-period (2008-2012) instead

\section{Seasonal Cycle of Ocean Heat Storage}

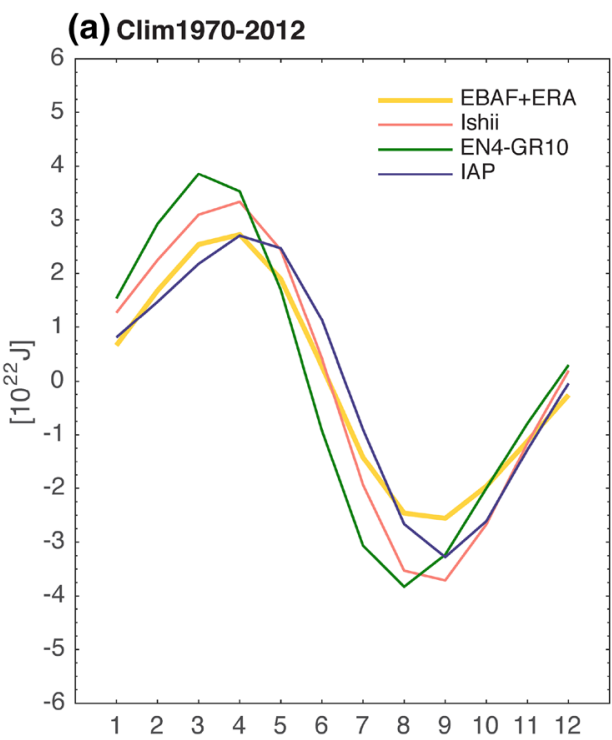


analysis shows similar amplitude and phase in both periods. Although the seasonal cycles during a long-period climatology is less affected by ENSO events, it will be affected more by the error due to less data coverage before the Argo period especially for Ishii and EN4-GR10 analyses. In other words, IAP analysis provides more robust estimate for seasonal $\mathrm{OHC}$ variations.

The discrepancies mainly exist during boreal Autumn both in amplitude and phase. Several possible reasons account for the uncertainty: (1) insufficient data in high-latitude oceans and marginal seas, as investigated in (McKinnon and Huybers 2016); (2) uncertainty in the ERA-interim reanalysis datasets and TOA radiative flux; and (3) the OHC changes below $1500 \mathrm{~m}$ might play a role.

\subsubsection{The probability density distribution of $\mathrm{OHC}$ in Southern Ocean}

In Fig. 3, a much smaller and smoother variability is found in the Southern Ocean OHC for the Ishii data. We argue that it is probably due to the sparse distribution of in-situ data and the mapping method which is not able to reconstruct the real ocean variability. The Ishii mapping method used zero anomalies as a first-guess, assuming no change in the data-sparse regions. So the reconstruction in the data gaps might be strongly affected by the first-guess and create a "no data, no signal" error. The probability density function (PDF) distribution of the $\mathrm{OHC}$ anomalies provides useful insights (Fig. 11 upper panel). If the analyses field drifts to the first guess (zero), there may be larger peak of the OHC anomalies near zero. Ishii data (in dark blue) show consistently larger peaks near zero than the other two datasets, and the differences between Ishii and the other two datasets get smaller in the more recent decades. This behavior is more obvious in the Southern Ocean as is shown in the bottom panel of Fig. 11, since the Southern Ocean has the sparsest distribution of in-situ data.

\subsubsection{Geographical pattern of uncertainty and its possible link with data count}

It is clear that $\mathrm{OHC}$ estimates from individual dataset differ from each other and large uncertainty exists especially in the pre-Argo period. But why are the uncertainties in the Pacific and Southern Oceans larger than that in the other basins before 2005 (Fig. 1)? Here, we define the ensemble

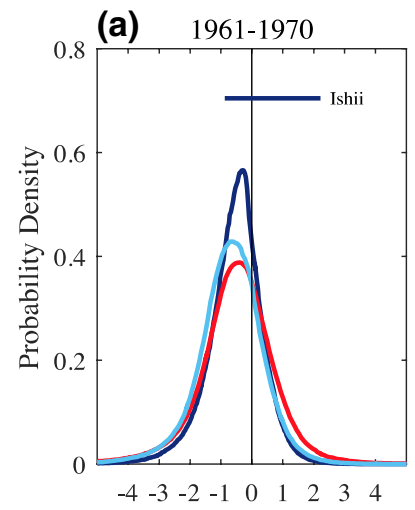

(b) $\quad 1971-1980$

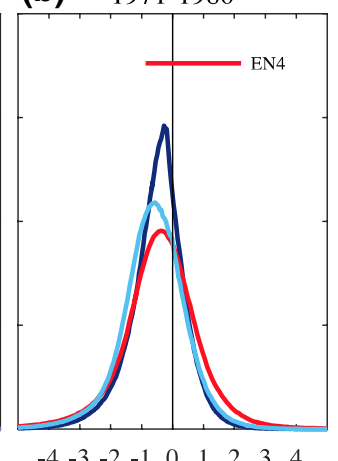

(f) OHC units: $10^{9} \mathrm{~J}$

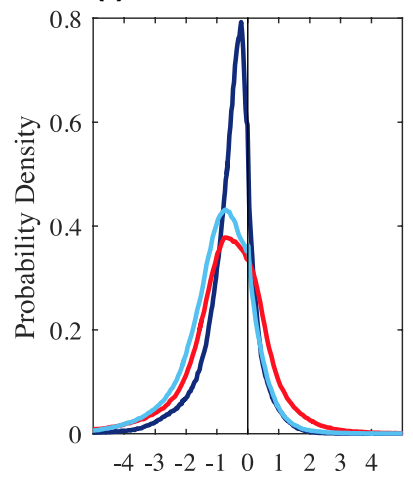

(g) OHC units: $10^{9} \mathrm{~J}$

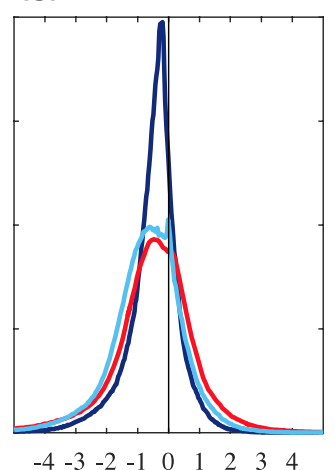

(c) $1981-1990$

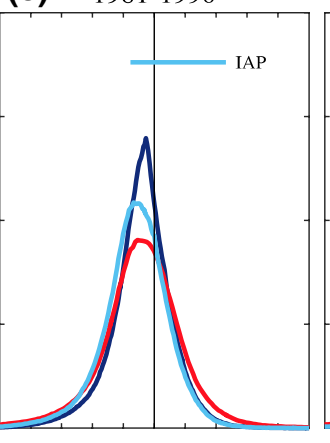

$\begin{array}{lllllllll}-4 & -3 & -2 & -1 & 0 & 1 & 2 & 3 & 4\end{array}$ (d) $1991-2000$

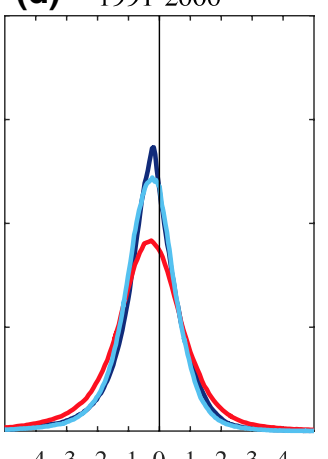

(h) OHC units: $10^{9} \mathrm{~J}$

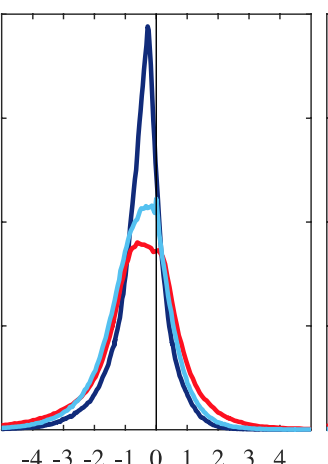

(i) OHC units: $10^{9} \mathrm{~J}$

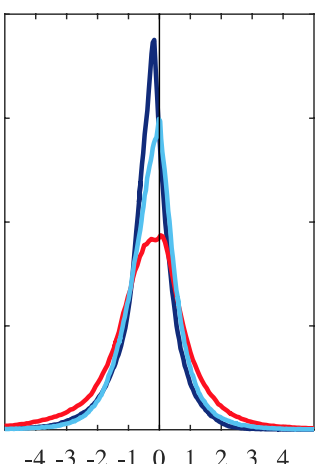

(e) 2001-2010

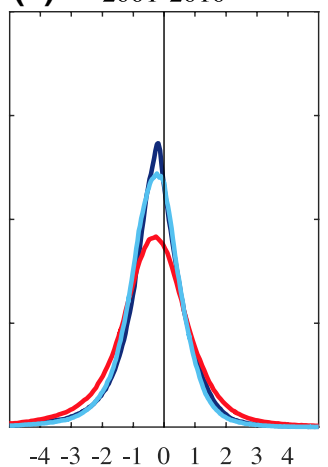

Fig. 11 Probability density functions of $\mathrm{OHC}$ anomalies during the past five decades from left to right revealed by three datasets, Ishii (dark blue), EN4-GR10 (red) and IAP (sky blue), the upper panels a-e are for the Global Ocean and the bottom panels $\mathbf{f}-\mathbf{j}$ are the results in the Southern Ocean 
mean (EM) and ensemble spread (ES) of OHC estimates in Eqs. 2 and 3, similar to Xue et al. (2017).

$E M(x, y, t)=\frac{1}{N} \sum_{k=1}^{N} X_{k}(x, y, t)$

$E S(x, y, t)=\sqrt{\frac{1}{N-1} \sum_{k=1}^{N}\left(X_{k}(x, y, t)-E M(x, y, t)\right)^{2}}$

where $X_{k}(x, y, t)$ denotes the OHC estimate from an individual analysis and $\mathrm{N}$ is the total number of the datasets. The ES, as described by Eq. 3, provides a measure of difference among objective analyses in a way similar to the ensemble spread used in ensemble forecasting.

The geographical pattern of ensemble spread is shown in Fig. 12 and the numbers in the figure indicate the areaaveraged ES of each ocean basin in two successive periods (1970-2004, the pre-Argo era; 2005-2012, the Argo era). The area-averaged ES values decrease in each ocean basin during the last decade, indicating that Argo project helps to dramatically increase the accuracy of ocean subsurface analysis. The ES in the west boundary currents (Kuroshio Current, the Gulf Current etc.) and the Antarctic Circumpolar Current (ACC) regions are larger than the other locations, because these regions contain rich meso-scale eddies. Even the Argo network is insufficient in representing the ocean variabilities at these regions. In the Southern Hemisphere (south of $20^{\circ} \mathrm{S}$ ), the three datasets always show large discrepancies pre 2004. This is linked to both rich meso-scale variabilities in ACC regions and poor data coverage in the Southern Hemisphere before Argo. Therefore, our results encourage an enhanced observing system with better capability of monitoring the regions with large gradient in the future.

\section{Discussions and summary}

This study compares the $\mathrm{OHC}$ changes in the three gridded subsurface temperature datasets for four major ocean basins. The findings confirm that each ocean basin has experienced a robust warming in the past three decades. And the basin integral of $\mathrm{OHC}$ estimates in the Atlantic and the Indian Oceans show smaller uncertainty since the 1970s compared to the Pacific and Southern Oceans due to the disproportionate area. A robust geographical distribution of $\mathrm{OHC}$ changes can be detected for all products, although the interpretation for the geographical pattern requires further analysis (Xie et al. 2015). Apparent discrepancies were also found among the products, especially in the Pacific and Southern Oceans.

It is helpful to compare the $\mathrm{OHC}$ changes in each ocean basin in the recent decade (1998-2012) to review the key findings in the current hiatus-related literatures. Figure 13 shows OHC changes based on the three datasets, including the upper 700-m OHC change in the Indian Ocean (as calculated in Lee et al. 2015), OHC between 100-to-300-m depth in the Indo-Pacific basin (as calculated in Nieves et al. 2015), OHC below 300-m in the Atlantic and Southern Ocean (as calculated in Balmaseda et al. 2013; Chen
Fig. 12 Geographical pattern of the ensemble spread estimated from individual datasets in two successive periods: 1970-2004 (a) and 2005-2012 (b), with numbers indicating the area mean of each basin and the black solid line stands for the north boundary of Southern Ocean

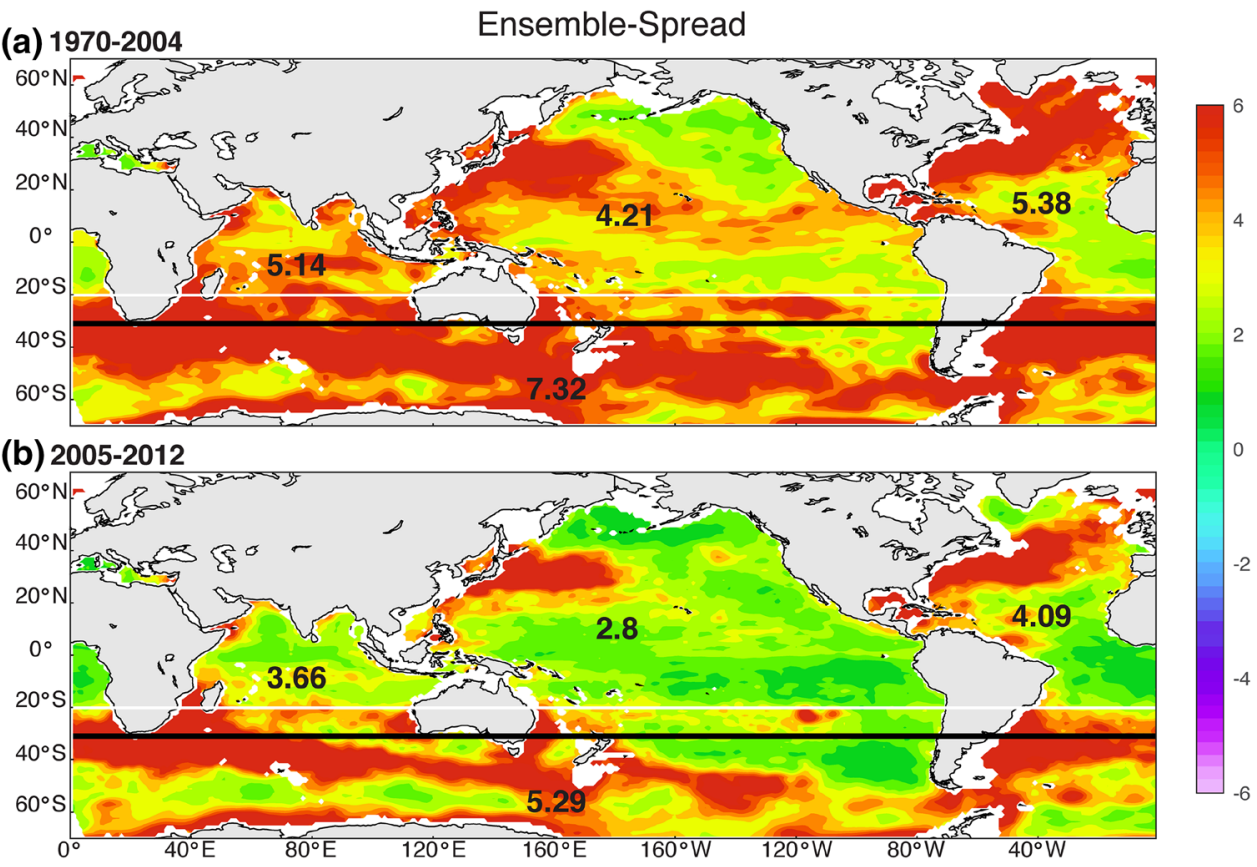


Fig. 13 OHC trends at different basins and depth intervals revealed by different datasets during 1998-2012. In700 is the upper 700-m OHC in the Indian Ocean, Indo-Pa100to300 is OHC between 100 and 300-m layer in total Indian Ocean and Pacific, Pa100to300 is the OHC between 100 and 300-m layer in Pacific, Atl300to1500 and So300to1500 are the $\mathrm{OHC}$ between 300 and $1500-\mathrm{m}$ in Atlantic and the Southern Ocean respectively. The trends of global OHC $(0-1500 \mathrm{~m})$ change during the same period are shown on the right end

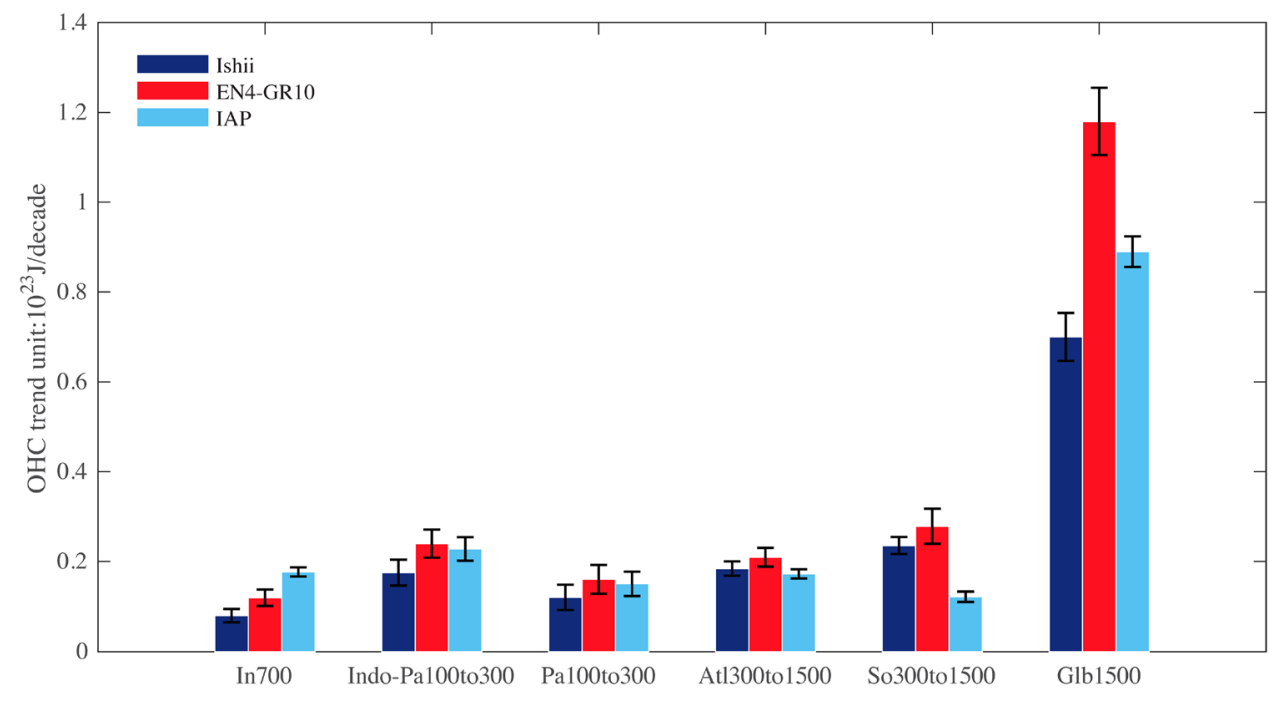

and Tung 2014; Drijfhout et al. 2014) and OHC between 100-to-300-m depth in the Pacific Ocean (as calculated in Meehl et al. 2011). It is apparent that all of these regions are ocean heat sinks in the current decade, but there is no clear indication of which ocean basin dominates the global OHC change.

Substantial uncertainty in the decadal $\mathrm{OHC}$ redistribution globally among the three datasets prevents reaching a conclusion about the relative contribution of each basin to the global $\mathrm{OHC}$ changes. To understand the relation between $\mathrm{OHC}$ changes and the global warming slowdown/ hiatus, we need quantify the storage of heat not only during the hiatus period but also during the decades before the hiatus. So we recommend a comprehensive evaluation in the future to quantify the impact of insufficient ocean sampling on historical $\mathrm{OHC}$ calculations, i.e. the performance of different mapping methods. A recent study (Cheng et al. 2017) used data during Argo period as "truth", and then subsampled the "truth" according to the historical sampling. By comparing the reconstructed field with the "truth", the accuracy of the reconstruction can be assessed. This study showed a reliable reconstruction for IAP mapping for decadal and multi-decadal OHC variations in the major ocean basins. Similar tests are highly recommended in the future.

Current observation system, covering mostly region of global ocean, increases the accuracy of OHC estimates and reduces the disagreement between different datasets compared with the pre-Argo era. But OHC estimates among oceans with more energetic oceanic phenomena such as ocean fronts and meso-scale eddies, still have large uncertainty in the Argo era. The current observation system should be maintained and extended in the future to be achieve a more complete ocean sampling.

Since one can never re-observe the ocean in the past, some synthetic data should be used, for instance high-resolution model outputs, sea level data, etc. Furthermore, data during the Argo period are still insufficient to observe the meso-scale eddies and $\mathrm{OHC}$ changes related to weather phenomena. Therefore, high-resolution models and sea level data will be helpful for the further evaluation of the current $\mathrm{OHC}$ analyses. Such a practice will significantly improve the understanding of the uncertainty in OHC estimates and facilitate more accurate reconstruction of historical OHC changes.

Acknowledgements L. Cheng is supported by National Natural Science Foundation of China (41506029, 2016YFC1401806 and 41476016) and C. Li is supported by the National "973" Programme (No. 2013CB956203) and the National Natural Science Foundation of China (41490642).

Open Access This article is distributed under the terms of the Creative Commons Attribution 4.0 International License (http:// creativecommons.org/licenses/by/4.0/), which permits unrestricted use, distribution, and reproduction in any medium, provided you give appropriate credit to the original author(s) and the source, provide a link to the Creative Commons license, and indicate if changes were made.

\section{References}

Abraham JP, Baringer M, Bindoff NL et al (2013) A review of global ocean temperature observations: implications for ocean heat content estimates and climate change: review of ocean observations. Rev Geophys 51:450-483. doi:10.1002/rog.20022

Allan RP, Liu C, Loeb NG et al (2014) Changes in global net radiative imbalance 1985-2012. Geophys Res Lett 41:5588-5597. doi:10. 1002/2014GL060962

Balmaseda MA, Trenberth KE, Kaellen E (2013) Distinctive climate signals in reanalysis of global ocean heat content. Geophys Res Lett 40:1754-1759. doi:10.1002/grl.50382

Boyer TP, Antonov JI, Baranova OK, Coleman C, Garcia HE, Grodsky A, Johnson DR, Locarnini RA, Mishonov AV, O'Brien TD, Paver CR, Reagan JR, Seidov D, Smolyar IV, Zweng MM (2013) 
World Ocean Database 2013. In: Levitus S, Mishonov A (eds) NOAA Atlas NESDIS 72, p 209

Boyer T, Domingues CM, Good SA et al (2016) Sensitivity of global upper-ocean heat content estimates to mapping methods, XBT bias corrections, and baseline climatologies. J Clim 29:48174842. doi:10.1175/JCLI-D-15-0801.1

Chen X, Tung KK (2014) Varying planetary heat sink led to globalwarming slowdown and acceleration. Science 345:897-903. doi:10.1126/science. 1254937

Cheng L, Zhu J (2014) Artifacts in variations of ocean heat content induced by the observation system changes. Geophys Res Lett 41:7276-7283. doi:10.1002/2014GL061881

Cheng L, Zhu J (2015) Influences of the choice of climatology on ocean heat content estimation. J Atmos Ocean Technol 32:388394. doi:10.1175/JTECH-D-14-00169.1

Cheng L, Zhu J (2016) Benefits of CMIP5 multimodel ensemble in reconstructing historical ocean subsurface temperature variations. J Clim. doi:10.1175/JCLI-D-15-0730.1

Cheng L, Zhu J, Cowley R et al (2014) Time, probe type, and temperature variable bias corrections to historical expendable bathythermograph observations. J Atmos Ocean Technol 31:17931825. doi:10.1175/JTECH-D-13-00197.1

Cheng L, Zheng F, Zhu J (2015a) Distinctive ocean interior changes during the recent warming slowdown. Sci Rep. doi:10.1038/ srep14346

Cheng L, Zhu J, Abraham J (2015b) Global upper ocean heat content estimation: recent progress and the remaining challenges. Atmos Ocean Sci Lett 8:333-338. doi:10.3878/AOSL20150031

Cheng L, Abraham J, Goni G et al (2016) XBT science: assessment of instrumental biases and errors. Bull Am Meteorol Soc 97:924933. doi:10.1175/BAMS-D-15-00031.1

Cheng L, Trenberth KE, Fasullo J et al (2017) Improved estimates of ocean heat content from 1960 to 2015. Sci Adv 3:e1601545. doi:10.1126/sciadv. 1601545

Church JA, White NJ, Arblaster JM (2005) Significant decadal-scale impact of volcanic eruptions on sea level and ocean heat content. Nature 438:74-77. doi:10.1038/nature04237

Clement A, DiNezio P (2014) The Tropical Pacific Ocean-back in the driver's seat? Science 343:976-978. doi:10.1126/ science. 1248115

Deser C, Alexander MA, Xie S-P, Phillips AS (2010) Sea surface temperature variability: patterns and mechanisms. Annu Rev Mar Sci 2:115-143. doi:10.1146/annurev-marine-120408-151453

Drijfhout SS, Blaker AT, Josey SA et al (2014) Surface warming hiatus caused by increased heat uptake across multiple ocean basins. Geophys Res Lett 41:7868-7874. doi:10.1002/2014GL061456

Enfield DB, Mestas-Nuñez AM, Timble PJ (2010) The Atlantic multidecadal oscillation and its relation to rainfall and river flows in the continental. Geophys Res Lett 28:2077-2080. doi:10.1029/ 2000GL012745

England MH, McGregor S, Spence P et al (2014) Recent intensification of wind-driven circulation in the Pacific and the ongoing warming hiatus. Nat Clim Change 4:222-227. doi:10.1038/ nclimate 2106

Fasullo J, Nerem R (2016) Interannual variability in global mean sea level estimated from the CESM Large and last millennium ensembles. Water 8:491. doi:10.3390/w8110491

Fasullo JT, Trenberth KE (2008) The annual cycle of the energy budget. Part I: global mean and land-ocean exchanges. J Clim 21:2297-2312. doi:10.1175/2007JCLI1935.1

Good SA, Martin MJ, Rayner NA (2013) EN4: quality controlled ocean temperature and salinity profiles and monthly objective analyses with uncertainty estimates: the EN4 data set. J Geophys Res Oceans 118:6704-6716. doi:10.1002/2013JC009067

Gouretski V, Reseghetti F (2010) On depth and temperature biases in bathythermograph data: development of a new correction scheme based on analysis of a global ocean database. Deep Sea Res Part Oceanogr Res Pap 57:812-833. doi:10.1016/j. dsr.2010.03.011

Henley BJ, Gergis J, Karoly DJ et al (2015) A tripole index for the interdecadal Pacific Oscillation. Clim Dyn 45:3077-3090. doi:10.1007/s00382-015-2525-1

Ishii M, Kimoto M (2009) Reevaluation of historical ocean heat content variations with time-varying XBT and MBT depth bias corrections. J Oceanogr 65:287-299. doi:10.1007/ s10872-009-0027-7

Ishii M, Kimoto M, Kachi M (2003) Historical ocean subsurface temperature analysis with error estimates. Mon Weather Rey 131:51-73. doi:10.1175/1520-0493(2003)131<0051:HOSTAW $>2.0 . \mathrm{CO} ; 2$

Johnson GC, Lyman JM, Purkey SG (2015) Informing deep Argo array design using Argo and full-depth hydrographic section data. J Atmos Ocean Technol 32:2187-2198. doi:10.1175/ JTECH-D-15-0139.1

Kosaka K, Xie SP (2013) Recent global-warming hiatus tied to equatorial Pacific surface cooling. Nature 501:403-407. doi:10.1038/ nature12534

Lee S-K, Park W, Baringer MO et al (2015) Pacific origin of the abrupt increase in Indian Ocean heat content during the warming hiatus. Nat Geosci 8:445-U41. doi:10.1038/NGEO2438

Levitus S, Antonov JI, Boyer TP et al (2009) Global ocean heat content 1955-2008 in light of recently revealed instrumentation problems. Geophys Res Lett 36:471-478. doi:10.1029/200 $8 \mathrm{GL} 037155$

Levitus S, Antonov JI, Boyer TP et al (2012) World ocean heat content and thermosteric sea level change $(0-2000 \mathrm{~m}), 1955$ 2010. Geophys Res Lett 39:L10603-L10607. doi:10.1029/201 2GL051106

Liu W, Xie S-P, Lu J (2016) Tracking ocean heat uptake during the surface warming hiatus. Nat Commun. doi:10.1038/ ncomms 10926

Loeb NG, Lyman JM, Johnson GC et al (2012) Observed changes in top-of-the-atmosphere radiation and upper-ocean heating consistent within uncertainty. Nat Geosci 5:110-113. doi:10.1038/ ngeo 1375

Lyman JM, Johnson GC (2014) Estimating global ocean heat content changes in the upper $1800 \mathrm{~m}$ since 1950 and the influence of climatology choice. J Clim 27:1945-1957

Lyman JM, Willis JK, Johnson GC (2006) Recent cooling of the upper ocean. Geophys Res Lett 33:510-527. doi:10.1029/200 6GL027033

Lyman JM, Good SA, Gouretski VV et al (2010) Robust warming of the global upper ocean. Nature 465:334-337. doi:10.1038/ nature 09043

McKinnon KA, Huybers P (2016) Seasonal constraints on inferred planetary heat content: seasonally constrained heat budget. Geophys Res Lett. doi:10.1002/2016GL071055

Meehl GA, Arblaster JM, Fasullo JT et al (2011) Model-based evidence of deep-ocean heat uptake during surface-temperature hiatus periods. Nat Clim Change 1:360-364. doi:10.1038/ NCLIMATE1229

Nieves V, Willis JK, Patzert WC (2015) Recent hiatus caused by decadal shift in Indo-Pacific heating. Science 349:532-535. doi:10.1126/science.aaa4521

Rhein M, Rintoul SR, Aoki S (2013) Observations: ocean. In: Climate change 2013: the physical science basis. Contribution of working group I to the fifth assessment report of the intergovernmental panel on climate change. Cambridge University Press, Cambridge, New York

Riser SC, Freeland HJ, Roemmich D et al (2016) Fifteen years of ocean observations with the global Argo array. Nat Clim Change 6:145-153. doi:10.1038/nclimate2872 
Roemmich D, Church J, Gilson J et al (2015) Unabated planetary warming and its ocean structure since 2006. Nat Clim Change 5:240-245. doi:10.1038/NCLIMATE2513

Trenberth KE (2015) Has there been a hiatus? Science 349:691-692. doi:10.1126/science.aac9225

Trenberth KE, Fasullo JT (2013) An apparent hiatus in global warming? Earths Future 1:19-32. doi:10.1002/2013EF000165.

Trenberth KE, Fasullo J, Balmaseda MA (2014a) Earth's energy imbalance. J Clim 27:3129-3144. doi:10.1175/ JCLI-D-13-00294.1

Trenberth KE, Fasullo JT, Kiehl J (2014b) Earth's global energy budget. Bull Am Meteorol Soc. doi:10.1175/2008BAMS2634.1

Trenberth KE, Fasullo JT, von Schuckmann K, Cheng L (2016) Insights into earth's energy imbalance from multiple sources. J Clim 29:7495-7505. doi:10.1175/JCLI-D-16-0339.1

von Schuckmann KV, Palmer MD, Trenberth KE et al (2016) An imperative to monitor Earth's energy imbalance. Nat Clim Change 6:138-144. doi:10.1038/nclimate2876
Wijffels S, Roemmich D, Monselesan D et al (2016) Ocean temperatures chronicle the ongoing warming of Earth. Nat Clim Change 6:116-118. doi:10.1038/nclimate2924

Xie S-P (2016) Oceanography leading the hiatus research surge. Nat Clim Change 6:345-346

Xie SP, Yu K, Okumura YM (2015) Distinct energy budgets for anthropogenic and natural changes during global warming hiatus. Nat Geosci. doi:10.1038/NGEO2581

Xue Y, Wen C, Kumar A et al (2017) A real-time ocean reanalyses intercomparison project in the context of tropical pacific observing system and ENSO monitoring. Clim Dyn. doi:10.1007/ s00382-017-3535-y

Yan X-H, Boyer T, Trenberth K et al (2016) The global warming hiatus: slowdown or redistribution? The global warming hiatus. Earths Future. doi:10.1002/2016EF000417 